\title{
Mechanisms Setting the Strength of Orographic Rossby Waves across a Wide Range of Climates in a Moist Idealized GCM
}

\author{
ROBERT C. J. WILLS \\ University of Washington, Seattle, Washington \\ TAPIO SCHNEIDER \\ California Institute of Technology, Pasadena, California
}

(Manuscript received 21 October 2017, in final form 30 May 2018)

\begin{abstract}
Orographic stationary Rossby waves are an important influence on the large-scale circulation of the atmosphere, especially in Northern Hemisphere winter. Changes in stationary waves with global warming have the potential to modify patterns of surface temperature and precipitation. This paper presents an analysis of the forcing of stationary waves by midlatitude orography across a wide range of climates in a moist idealized GCM, where latent heating and transient eddies are allowed to feed back on the stationary-eddy dynamics. The stationary-eddy amplitude depends to leading order on the surface winds impinging on the orography, resulting in different climate change responses for mountains at different latitudes. Latent heating is found to damp orographic stationary waves, whereas transient eddies are found to reinforce them. As the climate warms, the damping by latent heating becomes more effective while the reinforcement by transient eddies becomes less effective, leading to an overall reduction in orographic stationary wave amplitude. These effects overwhelm the influences of a reduced meridional temperature gradient and increased dry static stability, both of which increase the sensitivity of the free troposphere to orographic forcing. Together with a reduction in the midlatitude meridional temperature gradient, the weakening of orographic stationary waves leads to reduced zonal asymmetry of temperature and net precipitation in warm, moist climates. While circulation changes in this idealized model cannot be expected to agree quantitatively with changes in the real world, the key physical processes identified are broadly relevant.
\end{abstract}

\section{Introduction}

Large-scale orography such as the Tibetan Plateau, Rocky Mountains, and Andes influence the general circulation of the atmosphere by exciting planetaryscale stationary Rossby waves (Hoskins and Karoly 1981; Held et al. 2002) with consequences for the zonal variation of temperature (Lau 1979; Kaspi and Schneider 2011; Deser et al. 2014; Hoskins and Woollings 2015) and precipitation (Peixóto and Oort 1983, 1992; Broccoli and Manabe 1992; Wills and Schneider 2015, 2016). Orographic Rossby waves are particularly important for the dryness of central North America and Asia in winter (Broccoli and Manabe 1992), the maintenance of summertime subtropical circulation patterns (Rodwell and Hoskins 2001), and the seasonality and strength of precipitation

Corresponding author: Robert C. Jnglin Wills, rcwills@uw.edu in the East Asian monsoon region (Molnar et al. 2010; Chen and Bordoni 2014). The response of these regional climate features to global warming will thus depend on the response of orographic Rossby waves. Some studies have suggested that the strength of orographic stationary waves should increase with global warming as a result of the decreased lower-tropospheric meridional temperature gradient (Cook and Held 1988; Held 1993), but this is only one influence out of many on the amplitude of stationary waves.

Coupled climate models can give predictions of the stationary wave response to climate change over the next century (Stephenson and Held 1993; Joseph et al. 2004; Vecchi and Soden 2007; Brandefelt and Körnich 2008; Wang and Kushner 2011; Simpson et al. 2014, 2016). However, the stationary wave response in these models is a superposition of the response to several different stationary wave sources, complicating an assessment of the dominant physical mechanisms for 
these changes. Traditionally, stationary waves have been split into components attributed to different forcings using stationary wave models: general circulation models in which transient eddies are strongly damped (Ting and Yu 1998; Held et al. 2002) or that explicitly solve the linearized primitive equations (Egger 1976; Hoskins and Karoly 1981; Nigam et al. 1986, 1988; Valdes and Hoskins 1989; Ting 1994). The climatology and climate change response of stationary waves are well simulated by such models (Nigam et al. 1988; Stephenson and Held 1993), but they rely on specifying diagnosed diabatic tendencies, which themselves depend on the stationary wave solution. Stephenson and Held (1993) find that changes in latent heating and transient-eddy heat and momentum fluxes, rather than changes in the zonal-mean basic state, dominate the stationary wave response to global warming. This highlights the importance of understanding moist processes and transient eddies as they change with global warming. In the modern climate, much of the zonal asymmetry in latent heating and transient-eddy heating is either directly or indirectly a response to orography (Nigam et al. 1988). Thus, in order to study changes in diabatic tendencies associated with orography and their role in modifying orographic stationary Rossby waves under climate change, we use a moist general circulation model (GCM), where transient eddies are simulated explicitly and latent heating is allowed to feed back on the dynamics.

In Wills and Schneider (2016, hereinafter WS16), we present idealized GCM experiments in which individual topographic and ocean-heating zonal asymmetries are added to an aquaplanet. This allows an analysis of the differing responses to climate change of stationary waves forced by these two types of zonally asymmetric forcings. We simulate a wide range of climates from cold, dry climates (280-K global-mean surface temperature), where the influence of latent heating is negligible, to warm, moist climates (nearly 320-K global-mean surface temperature), where latent heating plays a leading-order role in modifying stationary-eddy circulations. The response of stationaryeddy vertical velocity to warming is characterized by a strong decrease with warming when stationary eddies are forced by equatorial heating, and by a nonmonotonic response to warming when stationary eddies are forced by midlatitude orography (WS16). The vertical velocity response, which is important for changes in precipitation minus evaporation, mirrors changes in the horizontal flow as a result of the linear vorticity balance in the lower troposphere (WS16). In Wills et al. (2017), we study the mechanisms responsible for the zonally asymmetric circulation changes in the equatorial heating experiment. Here, we focus on the mechanisms responsible for changes in the strength of stationary waves in the midlatitude orographic forcing experiment.

There is an expectation from quasi-geostrophic theory that the strength of orographic stationary waves should depend on the strength of the mean lowlevel winds at the latitude of the mountain (Hoskins and Karoly 1981; Held 1983; Held and Ting 1990). The role of the low-level winds arises from their role in setting the strength of topographic vertical motions, which influence the atmosphere through adiabatic cooling or heating. Nonlinear modification of the topographic vertical motions by the stationary wave response reduces the strength of the adiabatic cooling and heating tendencies (Chen and Trenberth 1988; Valdes and Hoskins 1991; Ringler and Cook 1997), but it does not change the conclusion that these adiabatic tendencies are the primary way in which orography influences the free troposphere. In the midlatitudes, this adiabatic cooling/heating can be balanced by meridional advection along the large meridional temperature gradient. This meridional flow perturbation sets up a stationary Rossby wave with eastward group velocity (Hoskins and Karoly 1981). The meridional wind response can be modified by additional heating tendencies, such as the latent heating associated with orographic vertical motion or the transient-eddy heat fluxes associated with initiation of a storm track downstream. We can analyze the mechanisms governing changes in the strength of the resulting stationary Rossby wave using an analysis of the thermodynamic equation over the orography (cf. Hoskins and Karoly 1981). This is effectively an analysis of the boundary condition for quasi-geostrophic theory, which is the only way in which topography explicitly enters the quasi-geostrophic equations (Hoskins and Karoly 1981; Vallis 2006).

Considering the importance of the low-level wind and the meridional temperature gradient (both of which vary strongly with latitude) for the orographic forcing of stationary waves, we expect the stationary wave response to climate change will depend on the latitude of orographic forcing. We therefore run simulations with topography at different latitudes, described in section 2 . The stationary wave response to climate change forced by increased greenhouse gas absorption is described in section 3. In section 4, we analyze the forcing of upslope and downslope orographic winds by surface flow over and around topography. In section 5, we analyze the thermodynamic equation over the orography to understand the mechanisms through which the atmosphere responds to the orographic vertical winds and determine the factors important in the climate change response. In 

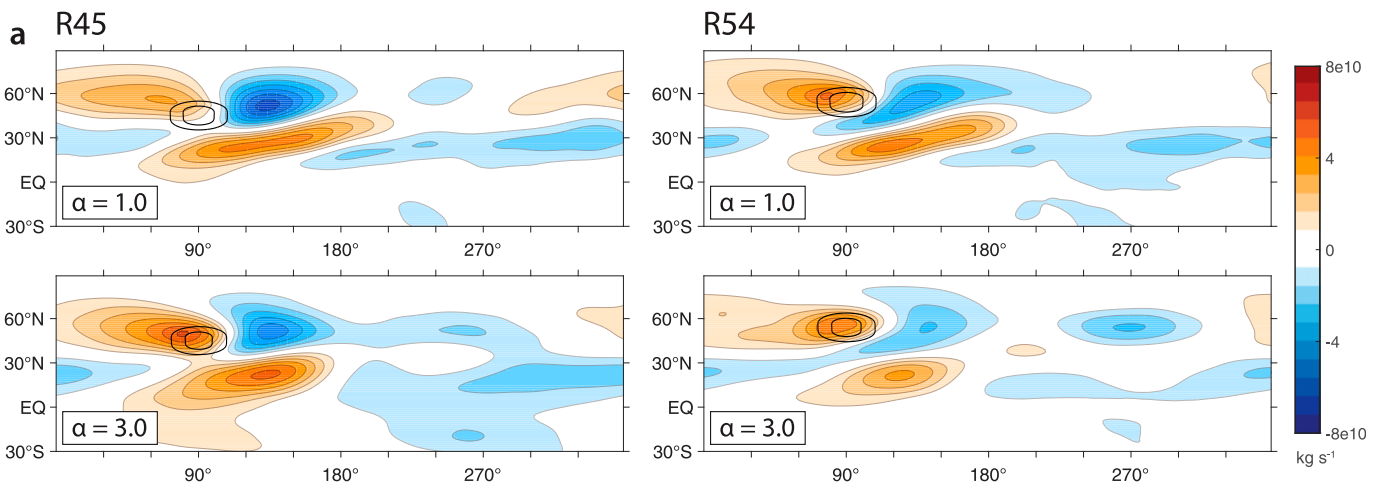

\section{b R45}
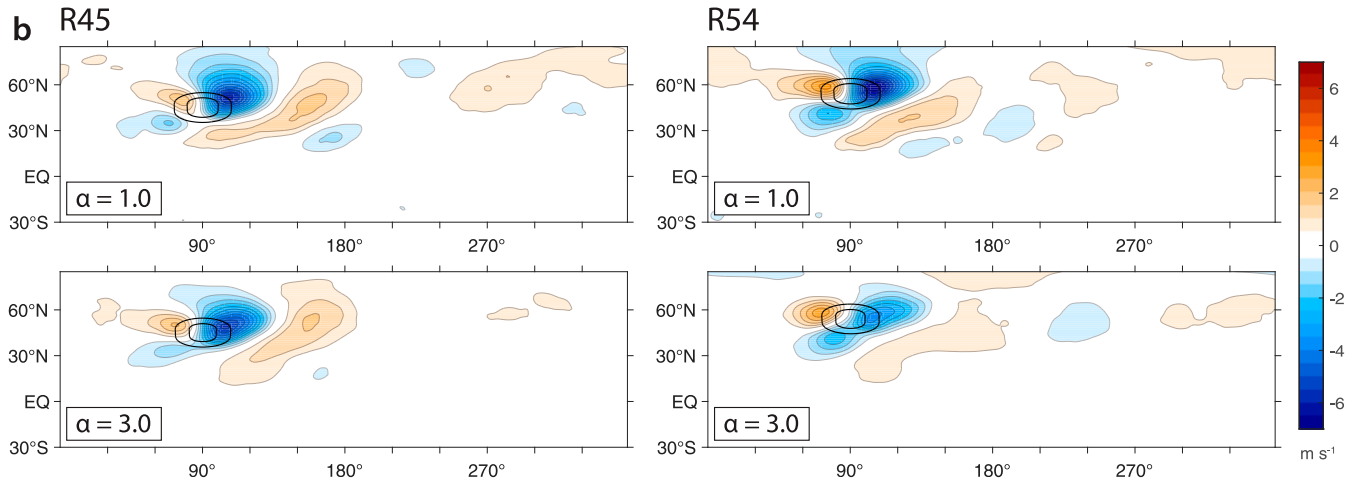

FIG. 1. (a) Barotropic streamfunction and (b) zonally anomalous lower-tropospheric $(550-750 \mathrm{hPa})$ meridional wind forced by orography in the reference simulation $\left(\alpha=1\right.$, global-mean surface temperature $\left.T_{g}=289 \mathrm{~K}\right)$ and in the 3 times optical depth simulation $\left(\alpha=3, T_{g}=307 \mathrm{~K}\right)$ for both mountain configurations (R45 and R54). The black contours show the 800 - and 900 -hPa contours of surface pressure.

section 6, we discuss how the stationary wave changes lead to a reduction in the midlatitude zonal variance of temperature and precipitation in the warmest climates studied. Section 7 summarizes the paper and presents our conclusions, and section 8 discusses the implications of our results for the real world.

\section{Idealized GCM experiments}

To isolate the response of orographically forced stationary Rossby waves to global warming, we add a single large-scale mountain ridge to an idealized GCM simulation with otherwise zonally symmetric aquaplanet boundary conditions. These simulations are described in WS16, which focuses on the response of the zonally asymmetric hydrological cycle to global warming. The model used is that of Frierson et al. (2006) and O'Gorman and Schneider (2008b), based on the GFDL Flexible Modeling System and the convection scheme of Frierson (2007). The model is run at T85 spectral resolution, with 38 levels in the vertical. There is a sponge layer in the top eight model levels in order to avoid reflections of planetary waves from the top of the domain, as described in WS16. Our simulations use a 1-m slab ocean mixed layer depth and a specified zonally symmetric ocean heat flux convergence that does not extend into latitudes where topography is present (see WS16).

The surface topography is specified as a function of longitude $\lambda$ and latitude $\phi$ by

$$
z_{s}(\lambda, \phi)=h_{0} \exp \left[-\frac{\left(\lambda-\lambda_{0}\right)^{2}}{2 \sigma_{\lambda}^{2}}-\frac{\max \left(0,\left|\phi-\phi_{0}\right|-R_{\phi}\right)^{2}}{2 \sigma_{\phi}^{2}}\right],
$$

where we use $h_{0}=2500 \mathrm{~m}, R_{\phi}=2.5^{\circ}, \sigma_{\phi}=5^{\circ}$, and $\sigma_{\lambda}=12.5^{\circ}$. We use two different orographic configurations, $\phi_{0}=45^{\circ}$ and $54^{\circ} \mathrm{N}$, which we refer to as $\mathrm{R} 45$ and R54, respectively. The profile of the topography in each experiment is shown in Fig. 1. The R45 experiment is set up to be qualitatively similar to the orographic forcing by the combined Rocky Mountains, Sierra Nevada, and Pacific Northwest Coastal Ranges and is the experiment studied in WS16. The R54 experiment is set up such that the latitude of the mountain coincides with the latitude of maximum change in zonal surface westerlies across the range of climates. 

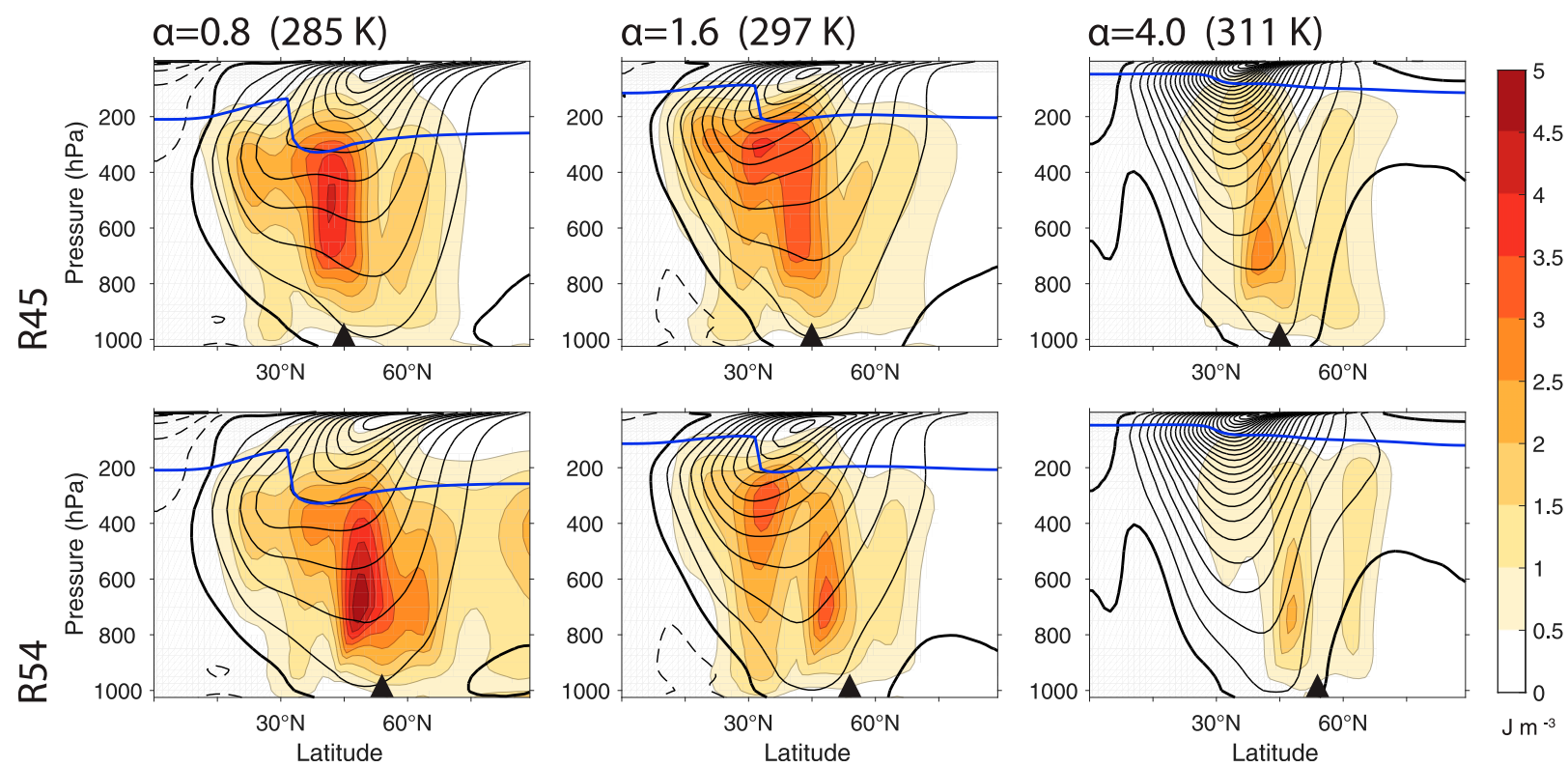

FIG. 2. Vertical profile of sEKE [Eq. (3)] superimposed on contours of the zonal-mean zonal wind (contour interval $5 \mathrm{~m} \mathrm{~s}^{-1}$, thick contour is the $[\bar{u}]=0$ line). (left)-(right) Three climates $(\alpha=0.8,1.6$, and 4.0) are shown for both the (top) R45 and (bottom) R54 experiments. Temperatures in parenthesis show the global-mean surface temperature. Also shown is the tropopause height computed from the $2 \mathrm{~K} \mathrm{~km}^{-1}$ lapse-rate criterion (blue line). The filled triangle in each plot shows the latitude of the topographic peak $\phi_{0}$.

To focus exclusively on the atmospheric response to orography, we keep the surface properties over topography the same as in the surrounding aquaplanet (i.e., the mountains are aquamountains). Note also that the idealized GCM does not consider the liquid-solid phase change, so there is no atmospheric ice condensate or sea ice over the elevated topography. The surface of the mountain differs from a land surface by its higher heat capacity, lower albedo, and lack of water limitation. The philosophy of this decision is that any modification of the surface boundary condition (e.g., albedo) would provide an additional source of stationary waves, with different physics, that should be studied separately.

We have investigated zonal mountain scales $\sigma_{\lambda}$ ranging from $2^{\circ}$ to $50^{\circ}$ longitude (Wills 2016). The stationary wave amplitude is maximum at $\sigma_{\lambda} \approx 15^{\circ}$. We chose $\sigma_{\lambda}=12.5^{\circ}$ to force a large-amplitude Rossby wave while keeping the mountain size realistic. For narrower mountains, the response is confined to the local orographic precipitation influence (cf. Shi and Durran 2014). At T85 resolution, there starts to be substantial grid-scale noise for $\sigma_{\lambda} \leq 5^{\circ}$. Such resolution issues are likely the cause of grid-scale noise in IPCC models (cf. Wills et al. 2016).

Global warming is simulated by rescaling the longwave optical depth $\tau=\alpha \tau_{\text {ref }}$ by a factor $\alpha$, where $\tau_{\text {ref }}$ is a reference optical depth that is a function of latitude and pressure (O'Gorman and Schneider 2008b): $\tau_{\text {ref }}(\phi, \tilde{p})=\left[f_{l} \tilde{p}+\left(1-f_{l}\right) \tilde{p}^{4}\right]\left[\tau_{e}+\left(\tau_{p}-\tau_{e}\right) \sin ^{2} \phi\right]$.

Here, $f_{l}=0.2, \tilde{p}$ is pressure expressed in nondimensional standard atmospheres, and the longwave optical thickness at the equator and at the pole are $\tau_{e}=7.2$ and $\tau_{p}=3.6$, respectively. Note that while the model uses sigma coordinates, the optical depth is specified as a function of pressure such that the atmospheric column is optically thinner over elevated topography. The optical depth in this model is not modified by water vapor or cloud radiative feedbacks and is thus fixed throughout each simulation. These simulations are "moist" principally because latent heating is allowed to feed back on the dynamics. We use 16 values of the rescaling factor $\alpha=[0.6,0.7,0.8,0.9,1.0,1.2,1.4,1.6,1.8,2.0,2.5,3.0,4.0$, 6.0], such that we simulate climates with global-mean surface temperatures ranging from 280 to $316 \mathrm{~K}$. Each simulation is spun up for nine years and averaged over the following eight years.

\section{Stationary wave response}

In each simulation, the time-mean barotropic streamfunction (Fig. 1a) or zonally anomalous meridional winds (Fig. 1b) shows a stationary Rossby wave emanating from the topography, with a wave train extending southeast into the tropics. The zonal wavenumber of the stationary wave is predominantly a mix of wavenumbers $1-4$ and does not show a large change with warming. While 


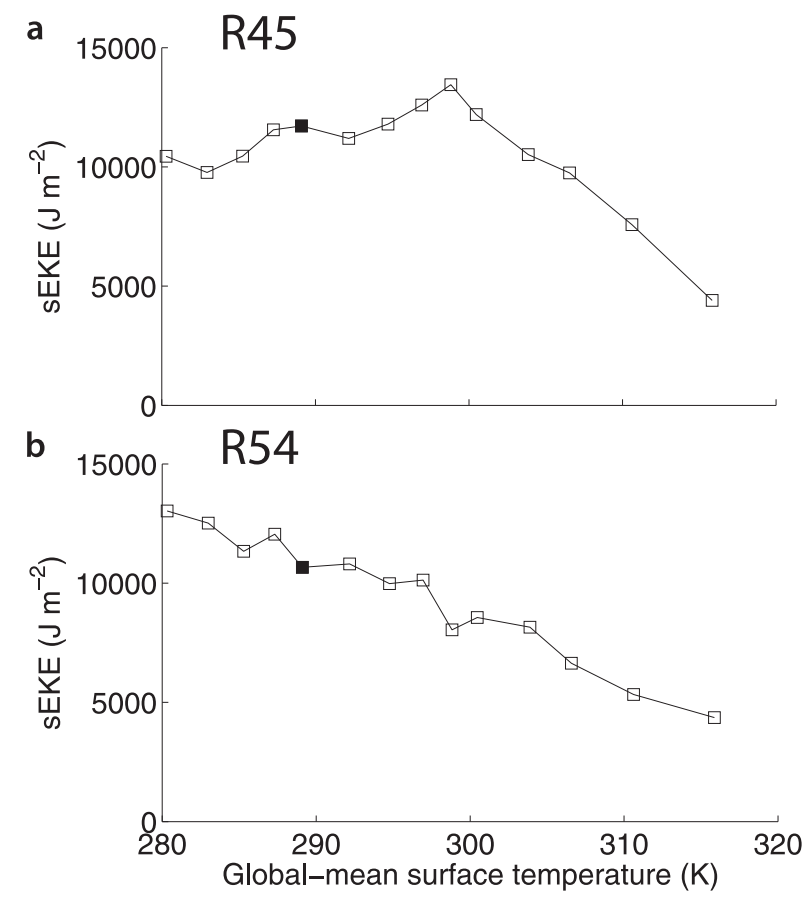

FIG. 3. Variation of global-mean vertically integrated sEKE with global warming in the (a) R45 and (b) R54 experiments. The sEKE is vertically integrated over the full column. Filled symbols indicate the reference climate $(\alpha=1)$.

length scale changes resulting from strengthening of the upper-tropospheric jet stream have been implicated in the stationary wave response to climate change over the next century (Simpson et al. 2016), the length scale of the stationary waves is too large for this to be an important mechanism in our simulations, since it is important primarily for zonal wavenumbers $k>4$. Length scale changes may be an important factor in the climate response of stationary waves forced by orography with a smaller zonal scale.

The stationary wave ray paths (i.e., the southeastward trajectory of the wave train into the tropics) can be understood in terms of ray-tracing theory (Hoskins and Karoly 1981) and depend on the structure of the zonal-mean winds. The zonal-mean winds in the idealized GCM (contours in Fig. 2) are not particularly realistic; they lack a distinct upper-tropospheric maximum and show an equatorward shift of the surface westerlies with climate change. Therefore, investigation of the precise ray paths and spatial structure of the stationary Rossby waves in this model would not necessarily lead to insights about stationary wave changes in the real world. Instead, we focus on the mechanisms controlling the strength of stationary waves, which should translate to more realistic settings.
We measure the strength of stationary Rossby waves by the stationary-eddy kinetic energy,

$$
\mathrm{sEKE} \equiv \frac{1}{2} \rho\left(\bar{u}^{* 2}+\bar{v}^{* 2}\right),
$$

a bulk measure of the stationary-eddy wind strength. Here, $u$ is the zonal wind, $v$ is the meridional wind, and $\rho$ is the time- and zonal-mean density. Stationary eddies are characterized by time-mean deviations from the zonal mean,

$$
\overline{(\cdot)}^{*} \equiv \overline{(\cdot)}-\overline{[\cdot]},
$$

where time averages are denoted by $\overline{(\cdot)}$ and zonal averages are denoted by [·].

Stationary-eddy kinetic energy is distributed throughout the troposphere and lower stratosphere in the hemisphere of forcing (Fig. 2). The sEKE is high in the lower troposphere at the latitude of forcing, then grows with height following the direction of vertical and meridional propagation to a local maximum in the upper troposphere near the latitude of maximum zonal wind. The upper-tropospheric maximum reflects the refraction of Rossby waves into the jet stream (Hoskins and Karoly 1981). Note that the latitude-pressure profile of zonal-mean zonal wind does not differ significantly between R45 and R54 and can thus be thought of as independent of the latitude of topographic forcing. In most of the simulations shown here, a weaker secondary wave train can be seen propagating poleward from the mountain, consistent with ray-tracing theory (Hoskins and Karoly 1981).

The planetary waves studied here propagate vertically within the troposphere; all but the longest waves are evanescent beyond the tropopause. The vertical structure of sEKE within the troposphere is therefore determined largely by the stationary external mode (Held et al. 1985). The vertical dispersion of stationary Rossby waves is inhibited in warm climates because of the increased upper-tropospheric vertical winds (cf. Charney and Drazin 1961), which results from the stronger warming of the tropical upper troposphere relative to the extratropical upper troposphere-lower stratosphere. This primarily affects the distribution of sEKE in the stratosphere and upper troposphere (compare in particular the decay of sEKE above $500 \mathrm{hPa}$ for $\alpha=1.6$ and 4.0 in Fig. 2). This trapping of stationary waves in the lower troposphere may contribute to the reduction of sEKE in the warmest climates. It can equivalently be thought of as a consequence of the contrasting responses of the 

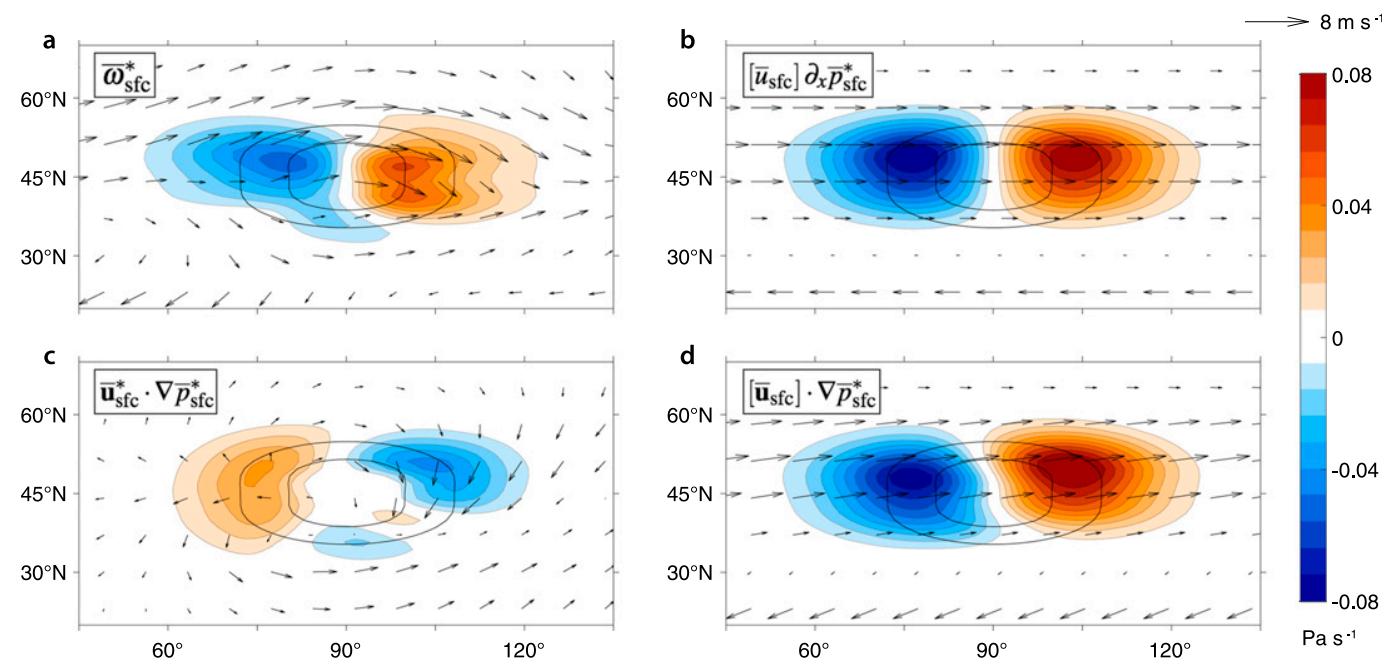

FIG. 4. (a) Map of $\bar{\omega}_{\text {sfc }}^{*}$ over topography (shading) in the reference climate of R45. Also shown are the horizontal surface winds ( $\overline{\mathbf{u}}_{\text {sfc }}$, vectors) and two contours $(900$ and $800 \mathrm{hPa})$ of surface pressure (black contours). (b)-(d) Components of $\bar{\omega}_{\text {sfc }}^{*}$ based on the decomposition in Eq. (6) and the corresponding surface wind vectors.

upper- and lower-tropospheric meridional temperature gradients, since the meridional temperature gradient sets the strength of stationary-eddy meridional wind required to balance a given heat source, as will be discussed in section 5 .

To average over any particular differences in stationary wave ray paths between simulations and focus on the global changes in the strength of stationary waves, we compute the global-mean vertically integrated sEKE. This measure still incorporates information about changes in the zonal, meridional, and height extent of stationary wave activity, which can arise because of changes in meridional and vertical dispersion, but it allows easy comparison between simulations with different stationary wave ray paths. There is an increase in global sEKE with warming in the R45 experiment until a global-mean surface temperature of $300 \mathrm{~K}(\alpha=1.8)$ is reached, at which point there is a pronounced reduction in sEKE with further warming (Fig. 3a). In contrast, the R54 experiment shows a monotonic reduction of global sEKE throughout the range of climates (Fig. 3b).

The main goal of this paper is to provide physical mechanisms for the response of the stationary wave amplitude to warming in these simulations. In particular, we hope to explain the reasons for the reduction of sEKE in the warmest climates and the differences in sEKE for mountains at different latitudes. While sEKE is just one possible measure of stationary wave amplitude, we have found that other measures (e.g., variance of barotropic streamfunction and wave activity) agree with the sense of change in stationary wave amplitude as diagnosed from sEKE. In most of what follows, we focus on the sEKE contribution from the meridional wind variance $\bar{v}^{* 2}$, which shows similar fractional changes to the total sEKE across the range of climates.

\section{Mechanical forcing by orography}

The principal means by which the atmosphere "feels" orography is through the mechanical compression of the atmospheric column. This results in net upward motion on the windward side of a mountain and net subsidence in the lee (Fig. 4a). The strength of the orographic vertical pressure velocity $\bar{\omega}_{\text {sfc }}$, in a long-term average, is set at the surface by the horizontal surface winds $\mathbf{u}_{\mathrm{sfc}}$ and the horizontal gradient of surface pressure $\nabla p_{s}$ over topography:

$$
\bar{\omega}_{\text {sfc }}=\overline{\mathbf{u}_{\text {sfc }} \cdot \nabla p_{s}} .
$$

Before we discuss the thermodynamics of the response to this perturbation in the next section, it is useful to discuss the controls on $\bar{\omega}_{\text {sfc }}$, because these factors help to explain stationary wave amplitude differences between the R45 and R54 experiments.

In the midlatitudes, the zonal-mean westerlies by themselves would lead to large orographic vertical velocities according to $\left[\bar{u}_{\mathrm{sfc}}\right] \partial_{x} \bar{p}_{s}$, leading to ascent on the western side of the mountain and descent on the eastern side (Fig. 4b). However, the stationary-eddy surface wind response reduces the strength of ascent/ descent as a result of the tendency of the climatological wind to follow surface pressure contours 

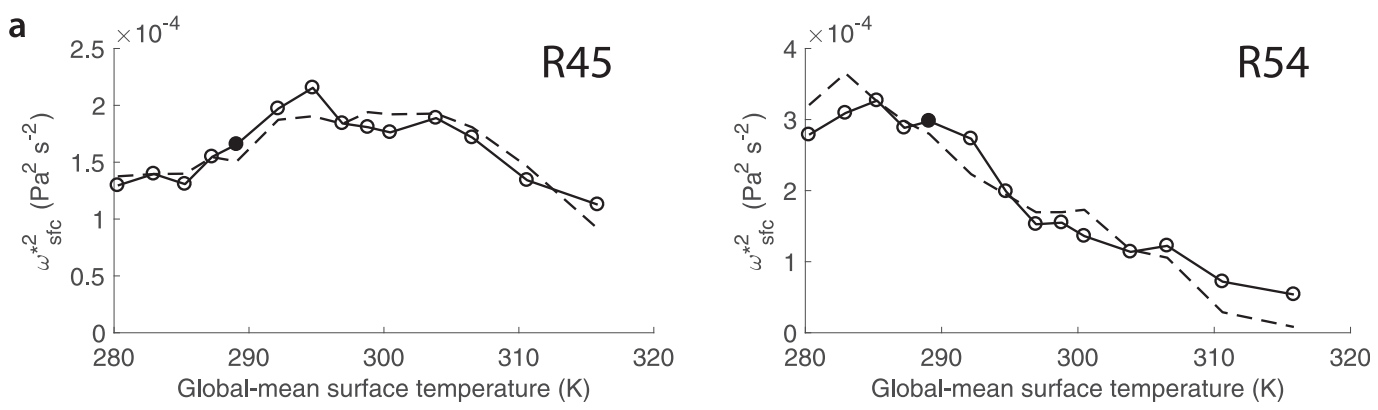

b
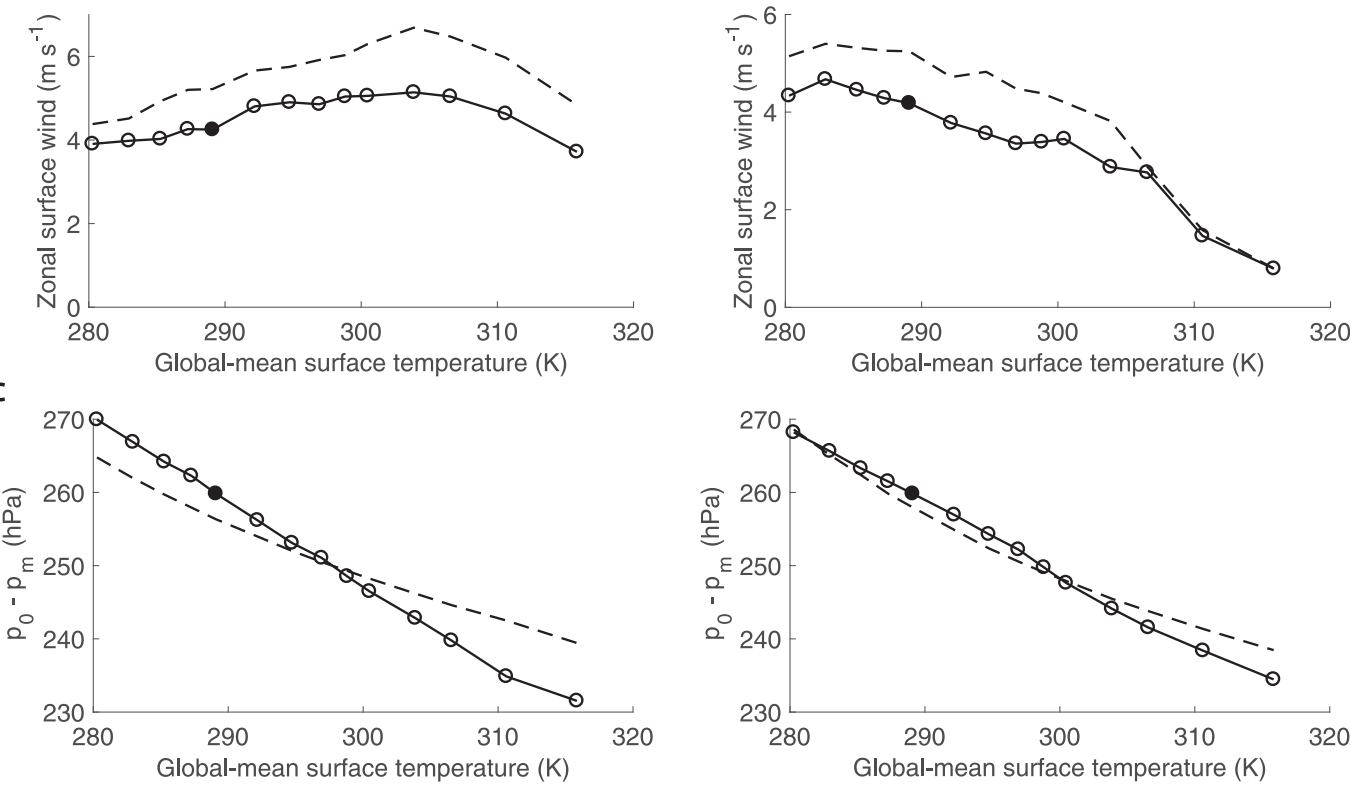

FIG. 5. Influences on orographic forcing by $\bar{\omega}_{\mathrm{sfc}}^{*}$. (a) Zonal-mean $\bar{\omega}_{\mathrm{sfc}}^{* 2}$ averaged within $5^{\circ}$ latitude of the mountain center in each experiment (solid line) and a scaling (7) based on $\left[\bar{u}_{\mathrm{sfc}}\right]$ (dashed line). The coefficient in the scaling ( 0.4 in R45 and 0.3 in R54) is chosen such that the average value over all climates is equal to the average value of $\bar{\omega}_{\mathrm{sfc}}^{* 2}$. (b) Average of $\left[\bar{u}_{\mathrm{sfc}}\right]$ within $5^{\circ}$ latitude of the mountain center in each experiment (solid line) and over the same range of latitudes in the Southern Hemisphere (dashed line). (c) Difference in surface pressure from the top of the mountain to a reference location at the same latitude, $p_{0}-p_{m}$ (solid line), and a scaling based on Eq. (10) (dashed line). The coefficient in the scaling is determined such that the average value over all climates is equal to the average value of $p_{0}-p_{m}$

around the mountain. This results in an opposing contribution to the orographic vertical velocity of the form $\overline{\mathbf{u}}_{\mathrm{sfc}}^{*} \cdot \nabla \bar{p}_{s}^{*}($ Fig. $4 \mathrm{c})$. This effect has been shown to reduce the amplitude of orographic stationary waves compared to linear models (Chen and Trenberth 1988; Valdes and Hoskins 1991; Ringler and Cook 1997) and leads to a sublinear dependence of orographic stationary wave amplitude on topographic height (Lutsko and Held 2016; Wills 2016). The full orographic vertical velocity can be expressed in terms of the components attributed to the zonal-mean and stationary-eddy surface winds according to

$$
\bar{\omega}_{\mathrm{sfc}}^{*} \approx\left(\left[\overline{\mathbf{u}}_{\mathrm{sfc}}\right]+\overline{\mathbf{u}}_{\mathrm{sfc}}^{*}\right) \cdot \nabla \bar{p}_{s}^{*}+\overline{\boldsymbol{v}}_{\mathrm{scc}}^{*} \partial_{y}\left[\bar{p}_{s}\right]
$$

The last term on the right-hand side of Eq. (6) is negligible because $\left|\nabla \bar{p}_{s}^{*}\right| \gg\left|\partial_{y}\left[\bar{p}_{s}\right]\right|$. The full zonal-mean wind term $\left[\overline{\mathbf{u}}_{\mathrm{sfc}}\right] \cdot \nabla \bar{p}_{s}^{*}$ (Fig. 4d), including the zonal-mean meridional surface winds, is the same magnitude as the zonal-mean zonal wind term (Fig. 4b), but the upslope vertical winds are shifted slightly to the southwest by the zonal-mean southerly winds in the midlatitudes. ${ }^{1}$

Although the zonal-mean zonal wind term, $\left[\bar{u}_{\mathrm{sfc}}\right] \partial_{x} \bar{p}_{s}$ is a factor of 2 larger than $\bar{\omega}_{\text {sfe }}^{*}$ one might expect them to scale similarly with warming. Basically, this is assuming

\footnotetext{
${ }^{1}$ We have neglected a contribution to Eq. (6) from the temporal correlations of the surface winds and the surface pressure gradients, $\overline{u_{\mathrm{scc}}^{\prime} \cdot \nabla p_{s}^{\prime}}$, which we find is negligible.
} 


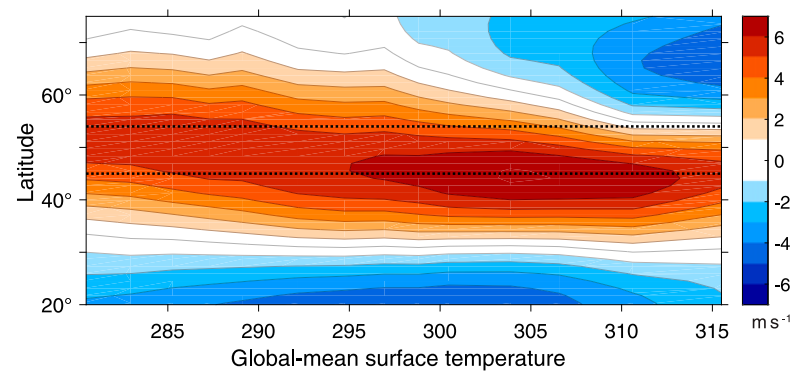

FIG. 6. Variation of zonal-mean zonal surface wind $\left[\bar{u}_{\mathrm{sfc}}\right]$ with warming across the range of climates. Zonal averages are shown for the Southern Hemisphere such that values are equivalent for R45 and R54. Northern Hemisphere winds are up to about $1 \mathrm{~m} \mathrm{~s}^{-1}$ weaker because of the presence of topography (Fig. 5b). Dashed lines indicate the latitude of the mountain center in each experiment.

that the flow is deflected around topography to the same extent in all simulated climates. In this case, the orographic vertical velocity variance would scale with the zonal-mean zonal wind according to

$$
\delta\left[\bar{\omega}_{\mathrm{scc}}^{*}\right] \sim \delta\left[\left[\bar{u}_{\mathrm{sfc}}\right]^{2}\left(\partial_{x} \bar{p}_{s}^{*}\right)^{2}\right] .
$$

We find that this scaling describes well the changes in $\bar{\omega}_{\text {sfc }}^{* 2}$ with warming in both experiments (Fig. 5a), except in the warmest two climates of the R54 experiment, where $\left[\bar{u}_{\text {sfc }}\right]$ at the latitude of the mountain is small. The constant of proportionality relating the left- and right-hand sides of Eq. (7) is 0.4 in R45 and 0.3 in R54, indicating that the stationary-eddy surface winds reduce the strength of mechanical orographic forcing by approximately $60 \%-70 \%$ (cf. Chen and Trenberth 1988; Valdes and Hoskins 1991; Ringler and Cook 1997).

Based on this scaling, the topographic vertical velocity reflects the zonal-mean zonal surface wind at the latitude of the mountain (Fig. 5b), which has a different warming response at different latitudes because of the equatorward shift of the surface westerlies with warming in the idealized GCM (Fig. 6). In these simulations, the $54^{\circ} \mathrm{N}$ mountain sees a monotonic decrease in the zonal-mean westerlies and the $45^{\circ} \mathrm{N}$ mountain sees a nonmonotonic change in the zonal-mean westerlies, responses that are reflected in the orographic vertical velocity changes. The equatorward shift of the zonal surface winds with warming mirrors the equatorward shift of upper-tropospheric transient-eddy kinetic energy (tEKE) in this idealized GCM (Wills 2016). This is in contrast to lower-tropospheric tEKE, which shifts poleward with warming, as seen also in observations and comprehensive climate models (Fyfe 2003; Yin 2005; Bender et al. 2012; Chang et al. 2012). The opposite direction of response in surface winds compared to observations and comprehensive models stems from the unrealistic structure of the upper-level winds in this gray-radiation idealized GCM and can be corrected by improving the representation of radiation (Z. Tan, 2017 personal communication). This paper aims to understand the mechanisms controlling the amplitude of orographic stationary waves as a function of mean climate state, rather than the climate response for a particular mountain range and mean climate state, so the equatorward shift of the zonal westerlies does not pose a serious problem here.

In addition to the effect of zonal surface wind changes, there is a small reduction in $\bar{\omega}_{\text {sfc }}^{* 2}$ with warming due to the reduction of topographic pressure gradients $\partial_{x} \bar{p}_{s}^{*}$ (Fig. 5c), which contribute to the scaling (7). The pressure gradient can be expressed in terms of the difference in time-mean surface pressure between the top of the mountain $p_{m}$ and a reference point at sea level $p_{0}$,

$$
\left[\left(\partial_{x} \bar{p}_{s}^{*}\right)^{2}\right] \approx\left(p_{m}-p_{0}\right)^{2} / \pi^{2} r_{e}^{2} \cos ^{2} \phi,
$$

where $r_{e}$ is the radius of Earth. ${ }^{2}$ The change is dominated by an increase in $p_{m}$, which weakens the orographic forcing of stationary waves in warmer climates by approximately $10 \%$ compared to the reference climate. Since $\nabla \bar{p}_{s}^{*}$ also shows up in the nonlinear term of Eq. (6), the influence of $p_{m}$ on the total orographic forcing should remain, no matter the structure of the surface winds.

The increase in top-of-mountain pressure $p_{m}$ is a simple thermodynamic consequence of the warming of the lower troposphere. Using hydrostatic balance, $\partial_{z} \ln p=-g / R T$, we may obtain an expression for the pressure at height $z_{m}$ (the height of the mountain) over a point where the surface pressure is $p_{0}$ by integrating vertically from the surface:

$$
\ln p\left(z_{m}\right) \approx \ln p_{0}-\int_{0}^{z_{m}} \frac{g}{R T} d z .
$$

Here, $R$ is the specific gas constant of dry air. Assuming that time-mean horizontal pressure differences at $z_{m}$ (normally of order $10 \mathrm{hPa}$ ) are much less than $p_{0}-p_{m} \sim$ $250 \mathrm{hPa}$, then $p\left(z_{m}\right) \approx p_{m}$. Substituting an approximate temperature profile $T(z)=T_{0}-\Gamma_{0} z$, we obtain an

\footnotetext{
${ }^{2}$ While the mountain length scale $\sigma_{\lambda}$ would show up in a scaling for the local $\partial_{x} \bar{p}_{s}^{*}$, the relevant length scale for the zonal-mean zonal pressure gradient variance $\left[\left(\partial_{x} \bar{p}_{s}^{*}\right)^{2}\right]$ is $\pi r_{e} \cos \phi$.
} 
expression for the top-of-mountain pressure in terms of a reference lapse rate $\Gamma_{0}$ and a reference surface temperature $T_{0}$,

$$
p_{m} \approx p_{0}\left(1-\frac{\Gamma_{0} z_{m}}{T_{0}}\right)^{g / R \Gamma_{0}} .
$$

Evaluating $T_{0}$ as an average surface temperature at the latitude of the mountain in the eastern hemisphere (away from the mountain) and $\Gamma_{0}$ as an average lapse rate over the bottom $250 \mathrm{hPa}$ of the troposphere in the same region, we obtain the approximate $p_{0}-p_{m}$ shown as a dashed line in Fig. $5 \mathrm{c}$. By fixing $T_{0}$ and $\Gamma_{0}$ independently (not shown), we can see that the increase in top-of-mountain pressure is a direct consequence of changes in surface temperature $T_{0}$; the influence of changes in $\Gamma_{0}$ is negligible for the range of climates studied here. This thermodynamic increase in top-of-mountain pressure has already been observed over the past century (Toumi et al. 1999).

The orographic vertical winds, which set the initial orographic perturbation to the atmosphere, are sensitive to changes in the zonal-mean zonal surface winds, in the top-of-mountain surface pressure, and in the stationary-eddy modification of surface winds. When the orography lies fully within the surface westerlies, the changes are determined largely by changes in the strength of the zonal-mean zonal surface winds. There is an additional tendency toward weaker forcing in warmer climates as the top-ofmountain surface pressure increases with warming. The orographic vertical velocity variance $\bar{\omega}_{\mathrm{sfc}}^{* 2}$ is the simplest measure that gives a qualitative sense of the strength of orographic forcing of stationary waves and the response of stationary wave amplitude (i.e., sEKE) to climate change in our simulations. In the next section, we will examine how the atmosphere responds to this mechanical surface forcing. It is worth noting that we designed the R54 experiment to get the maximum zonal surface wind response to climate change at the latitude of the mountain, with the hypothesis that as the zonal winds go to zero at this latitude, the stationary wave response would be dramatically reduced. This hypothesis was verified by these simulations.

\section{Thermodynamic response to orographic forcing}

To understand how the atmosphere responds to orographic vertical winds, we study the thermodynamic tendencies that balance the lower-tropospheric adiabatic cooling and heating induced by the orographic vertical winds. We examine the zonally anomalous steadystate thermodynamic balance,

$$
\left(\bar{u} \partial_{x} \bar{\theta}^{*}+\bar{v} \partial_{y} \bar{\theta}+\bar{\omega} \partial_{p} \bar{\theta}\right)^{*}+\nabla_{\rho} \cdot\left(\overline{\mathbf{v}^{\prime} \theta^{\prime}}\right)^{*}=\bar{Q}^{*} .
$$

Here, $\omega$ is the vertical pressure velocity, $\theta$ is the potential temperature, and

$$
\bar{Q}^{*}=\bar{Q}_{\text {latent }}^{*}+\bar{Q}_{\text {radiation }}^{*}+\bar{Q}_{\text {sub-grid }}^{*}
$$

is the zonally anomalous heating tendency by latent heating, radiation, and subgrid-scale turbulent mixing and convection. Deviations from a time average are denoted by primes such that $\nabla_{\rho} \cdot\left(\overline{\overline{\mathbf{v}}^{\prime} \boldsymbol{\theta}^{\prime}}\right)^{*}$ gives the zonally anomalous potential-temperature-flux divergence by transient eddies. ${ }^{3}$ The residual, which arises from the interpolation to pressure coordinates, is distributed between the zonal advection and transient-eddy terms as described in appendix A. The vertical profiles of the terms in the thermodynamic equation over the mountain are shown in Figs. 7 and 8 for the reference climate and a warmer climate, respectively, of the R45 experiment.

\section{a. Meridional wind response to vertical motions}

Over the mountain, the adiabatic cooling/heating $\left(\bar{\omega} \partial_{p} \bar{\theta}\right)^{*}$ is primarily balanced by stationary-eddy meridional advection $\left(\bar{v} \partial_{y} \bar{\theta}\right)^{*}$, a consequence of the large meridional temperature gradient in the midlatitudes. Both of these terms are dominated by zonal anomalies in wind rather than zonal anomalies in potential temperature, such that the dominant thermodynamic balance is

$$
\bar{v}^{*} \partial_{y} \overline{[\theta]} \approx-\bar{\omega}^{*} \partial_{p} \overline{[\theta]} .
$$

In this way, a stationary-eddy wind $\bar{v}^{*}$ is forced by flow over the mountain. If this simple two-term balance applied across the range of climates, $\bar{v}^{* 2}$ would be determined by the inverse square isentropic slope $\left(\partial_{y}[\bar{\theta}] / \partial_{p} \overline{[\theta]}\right)^{-2}$ and the vertical wind variance $\bar{\omega}^{* 2}$ (or approximately the orographic surface wind variance $\bar{\omega}_{\text {sfc }}^{* 2}$ ) according to

$$
\bar{v}^{* 2} \approx\left(\frac{\partial_{p} \overline{[\theta]}}{\partial_{y} \overline{[\theta]}}\right)^{2} \bar{\omega}^{* 2} \approx\left(\frac{\partial_{p} \overline{[\theta]}}{\partial_{y} \overline{[\theta]}}\right)^{2} \bar{\omega}_{\mathrm{sfc}}^{* 2} .
$$

\footnotetext{
${ }^{3}$ The transient-eddy potential temperature flux divergence, $\nabla_{\rho} \cdot\left(\overline{\mathbf{v}^{\prime} \theta^{\prime}}\right)^{*}$, is computed using density-weighted horizontal derivatives $\nabla_{\rho}$, such that it also includes the effects of temporal surface pressure fluctuations (cf. Boer 1982; WS16).
} 


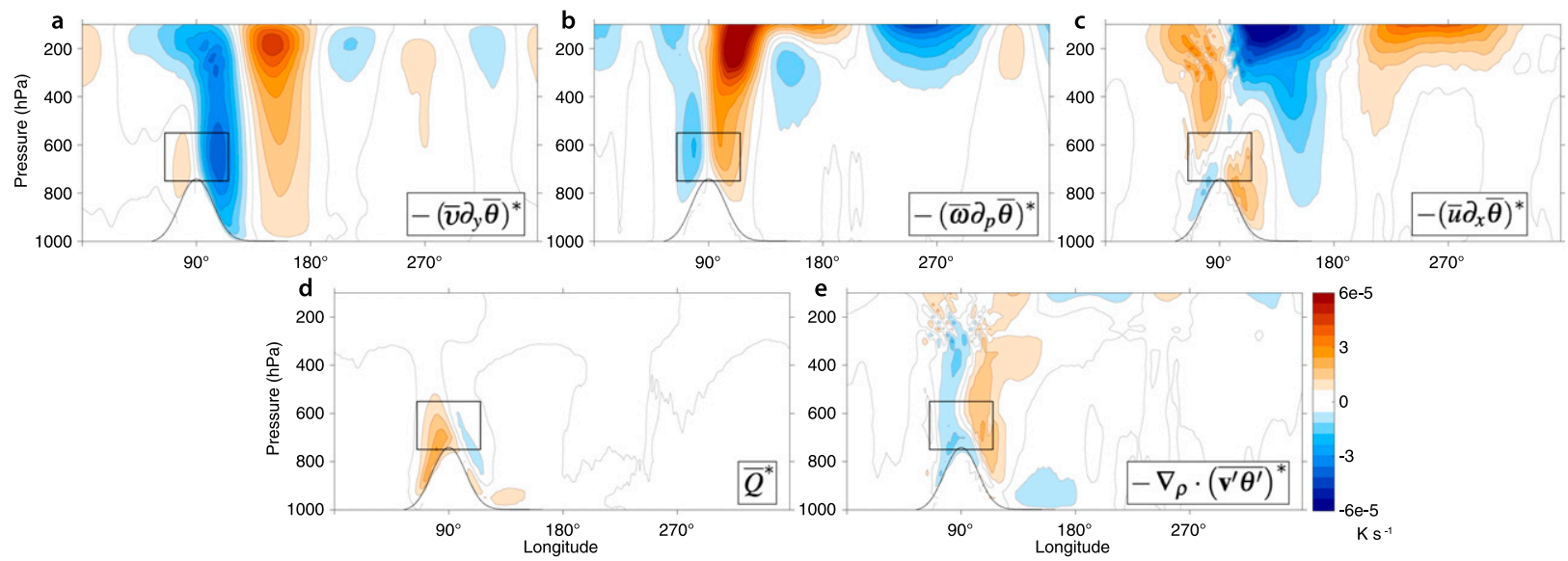

FIG. 7. Vertical profile of terms in the stationary-eddy thermodynamic equation [Eq. (11); units of $\mathrm{K} \mathrm{s}^{-1}$ ] averaged over $\phi \in\left[40^{\circ}, 50^{\circ}\right]$ in the reference climate $\left(\alpha=1.0, T_{g}=289 \mathrm{~K}\right)$ of R45. (a) Meridional, (b) vertical, and (c) zonal advection of potential temperature by stationary eddies. (d) All diabatic tendencies (latent heating, radiation, and parameterized boundary layer mixing). (e) Transient-eddy potential temperature flux convergence. Signs are chosen such that heating is red and cooling is blue. The residual is distributed among the zonal advection and transient-eddy terms as described in appendix B. A black line shows the time-mean surface pressure. (The black box over the mountain shows the averaging region used in Figs. 9 and 10.)

According to this framework, the sensitivity of stationaryeddy meridional winds to surface forcing is set by the inverse of the isentropic slope. This is equivalent to the perspective that the isentropic slope sets the extent to which flow goes over versus around topography (Valdes and Hoskins 1991). The isentropic slope in the lower troposphere generally decreases as the climate warms, because the meridional temperature gradient decreases and the static stability increases (IPCC 2013; Schneider and O'Gorman 2008). One would therefore expect the sensitivity of stationary-eddy meridional winds to surface forcing to increase as the climate warms. However, the terms we have ignored (zonally anomalous diabatic heating, transient-eddy heat flux convergence, and zonal advection) are not negligible in general, so this approximation gives only a qualitative sense of how orography forces stationary waves.

Particularly in the warmer climate $(\alpha=3.0$, Fig. 8$)$, latent heating (which is the dominant contributor to $\left.\bar{Q}^{*}\right)$ is large and out of phase with the adiabatic cooling/ heating. Therefore, latent heating damps the orographic forcing of stationary waves. An equivalent perspective is that latent heating helps air go over topography and thus reduces the extent to which the topography forces meridional motion. This damping becomes more effective with global warming because of the increase in atmospheric moisture content (see section $5 b$ ). The transient-eddy heat flux is also important; transient eddies move heat into the region downstream of the mountain that is cooled by meridional advection. This is in phase with the initial forcing

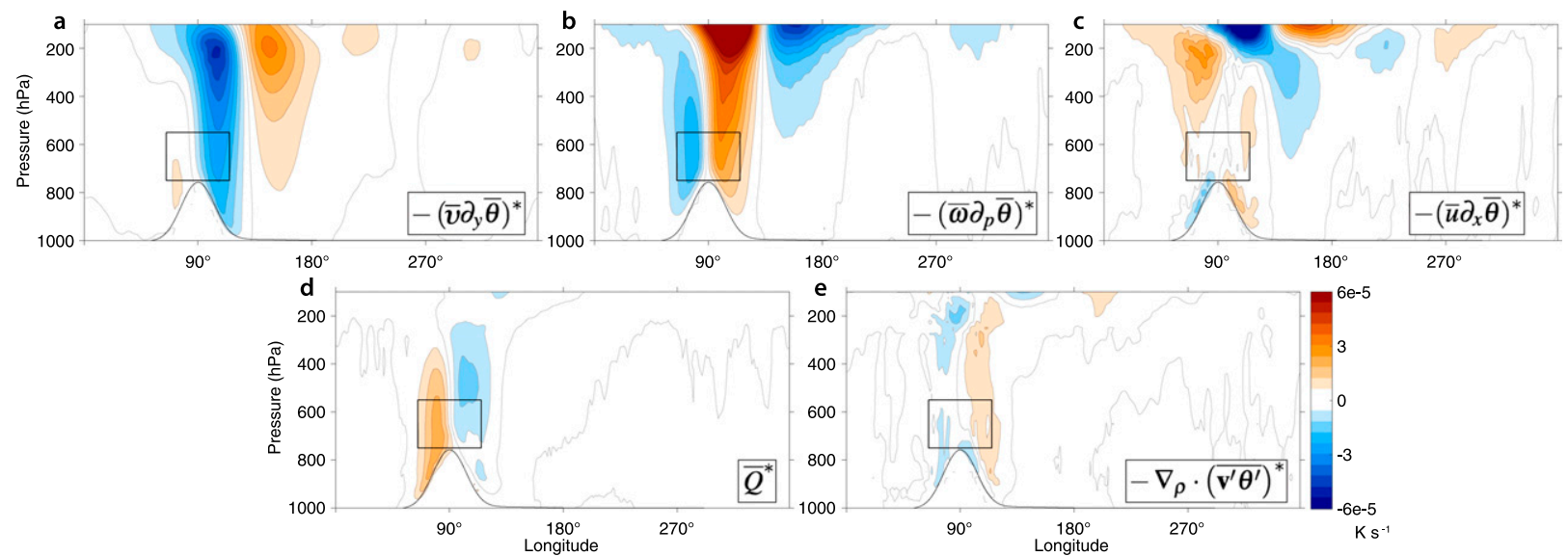

FIG. 8. As in Fig. 7, but for $\alpha=3.0\left(T_{g}=307 \mathrm{~K}\right)$ in the R45 experiment. 
by adiabatic cooling/heating and thus amplifies the stationary wave. This amplification becomes less effective with global warming because of decreases in temperature gradients and transient-eddy kinetic energy (see section 5c). Zonal advection plays a similar role to the transient-eddy heat fluxes in the lower troposphere, but it is a weaker effect and will not be a focus of this study.

To include these effects into a diagnostic theory for $\bar{v}^{* 2}$, we arrange the thermodynamic equation (11) into an equation for $\bar{v}^{*}$,

$$
\bar{v}^{*} \approx \frac{1}{\partial_{y} \bar{\theta}}\left(\bar{Q}^{*}-\nabla_{\rho} \cdot\left(\overline{\mathbf{v}^{\prime} \theta^{\prime}}\right)^{*}-\bar{u} \partial_{x} \bar{\theta}^{*}-\bar{\omega}^{*} \partial_{p} \bar{\theta}\right)^{*} .
$$

This equation simply states that, in the presence of a meridional temperature gradient, the net heating of zonal advection, vertical advection, transient-eddy heat fluxes, and diabatic terms is balanced by meridional advection. The only approximation applied thus far is to assume that the stationary-eddy meridional and vertical velocities, $\bar{v}^{*}$ and $\bar{\omega}^{*}$, are larger than the zonal-mean meridional and vertical velocities, $[\bar{v}]$ and $[\bar{\omega}]$. We make a budget for $\bar{v}^{* 2}$ by squaring Eq. (15) to get

$$
\bar{v}^{* 2} \approx \frac{1}{\left(\partial_{y} \bar{\theta}\right)^{2}}\left(Q^{2}+Z^{2}+W^{2}-2 Q(Z+W)+2 Z W\right)
$$

where $Q \equiv \bar{Q}^{*}-\nabla_{\rho} \cdot\left(\overline{\mathbf{v}^{\prime} \theta^{\prime}}\right)^{*}, \quad Z \equiv\left(\bar{u} \partial_{x} \bar{\theta}^{*}\right)^{*}, \quad$ and $W \equiv \bar{\omega}^{*} \partial_{p} \bar{\theta}$.

We apply the meridional wind variance budget to averages between 550 and $750 \mathrm{hPa}$, within $5^{\circ}$ latitude and $25^{\circ}$ longitude of the mountain center (denoted by $\{\cdot\}$; shown by boxes in Figs. 7 and 8 ). The 750 -hPa level is just above the mountain in the time mean. Focusing on this section of the lower troposphere allows us to diagnose how the troposphere responds to the initial orographic perturbation. The average stationary-eddy meridional wind $\bar{v}^{*}$ over these pressure levels is shown in Fig. 1b. The climate change response of $\left\{\bar{v}^{* 2}\right\}$ is qualitatively similar to the that of the global sEKE (Fig. 9a; cf. Fig. 3); it shows an increase with warming up to $300-\mathrm{K}$ global-mean surface temperature and decrease with further warming in the R45 experiment and a monotonic decrease with warming in the R54 experiment. However, there are quantitative differences between fractional $\left\{\bar{v}^{* 2}\right\}$ changes and fractional sEKE changes resulting from changes in horizontal wind anisotropy and changes in the extent to which Rossby waves propagate out of the orographic forcing region.

To account for the effect of zonal variations in meridional temperature gradients on the zonal variance of $v$, we define an effective meridional temperature gradient,

$$
\Lambda^{2}(\phi, p)=\frac{\left\{\left(\bar{v}^{*} \partial_{y} \bar{\theta}\right)^{2}\right\}}{\left\{\bar{v}^{* 2}\right\}}
$$

such that

$\left\{\overline{\boldsymbol{v}}^{* 2}\right\} \approx \frac{1}{\Lambda^{2}}\left\{Q^{2}+Z^{2}+W^{2}-2 Q(Z+W)+2 Z W\right\}$.

The hope is that $\Lambda$ behaves similarly to the zonal-mean meridional temperature gradient $\left|\partial_{y} \overline{[\theta]}\right|$ with warming. The effective meridional temperature gradient $\Lambda$ is larger than the zonal-mean meridional temperature gradient $\left|\partial_{y} \overline{[\theta]}\right|$, due to strong local meridional temperature gradients downstream of the mountain. However, it shows a similar response to climate change (Fig. 9c). The reduction in meridional temperature gradient with global warming increases the meridional wind response to a given forcing. To show the magnitude of this effect, we plot $\Lambda^{2}\left\{\overline{\boldsymbol{v}}^{* 2}\right\}$ in Fig. 9a. It is scaled to match $\left\{\overline{\boldsymbol{v}}^{* 2}\right\}$ in the reference climate such that it shows the $\left\{\bar{v}^{* 2}\right\}$ changes that would result without any changes in meridional temperature gradient. The role of the meridional temperature gradient in $\left\{\overline{\boldsymbol{v}}^{* 2}\right\}$ changes can thus be seen as the difference between the dashed and solid black lines in Fig. 9a.

The temperature tendency variance terms on the righthand side of Eq. (18) make up a diagnostic for $\Lambda^{2}\left\{\bar{v}^{* 2}\right\}$, as shown in Fig. 9b. In both experiments, the variance in adiabatic cooling/heating $W^{2}$ is the largest term. It increases with warming in R45 and decreases with warming in R54, contributing to the differing responses of $\Lambda^{2}\left\{\overline{\boldsymbol{v}}^{* 2}\right\}$ in these experiments (blue lines in Fig. 9b).

The adiabatic cooling/heating term can be further split up into influences from vertical velocity changes and from stratification changes:

$$
\left\{W^{2}\right\}=\Gamma^{2}\left\{\bar{\omega}^{* 2}\right\} .
$$

Here, $\Gamma$ characterizes the dry static stability felt by stationary-eddy circulations,

$$
\Gamma^{2}(\phi, p)=\frac{\left\{\left(\bar{\omega}^{*} \partial_{p} \bar{\theta}\right)^{2}\right\}}{\left\{\bar{\omega}^{* 2}\right\}} \equiv \frac{\left\{W^{2}\right\}}{\left\{\bar{\omega}^{* 2}\right\}}
$$

It is systematically smaller than the zonal-mean stratification $\left|\partial_{p} \overline{[\theta]}\right|$ in the coldest climates because the lower-tropospheric (i.e., $750 \mathrm{hPa}$ ) temperature is elevated in the vicinity of topography. It increases with warming beyond $295-\mathrm{K}$ global-mean surface temperature, roughly following changes in $\left|\partial_{p} \overline{[\theta]}\right|$ (Fig. 9d). This means that $W^{2}$ changes are similar to those computed 
a

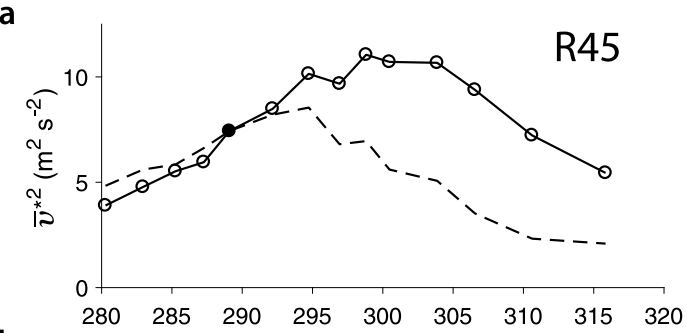

b

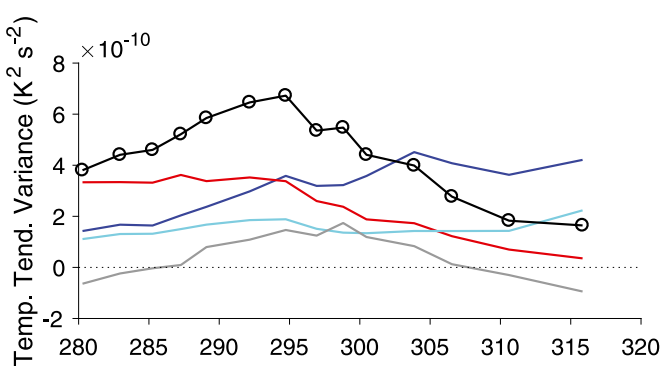

C

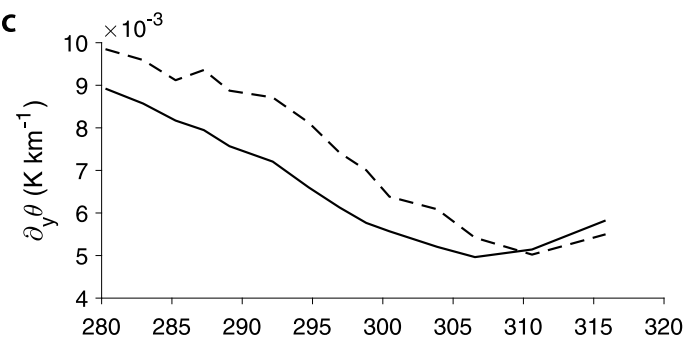

d
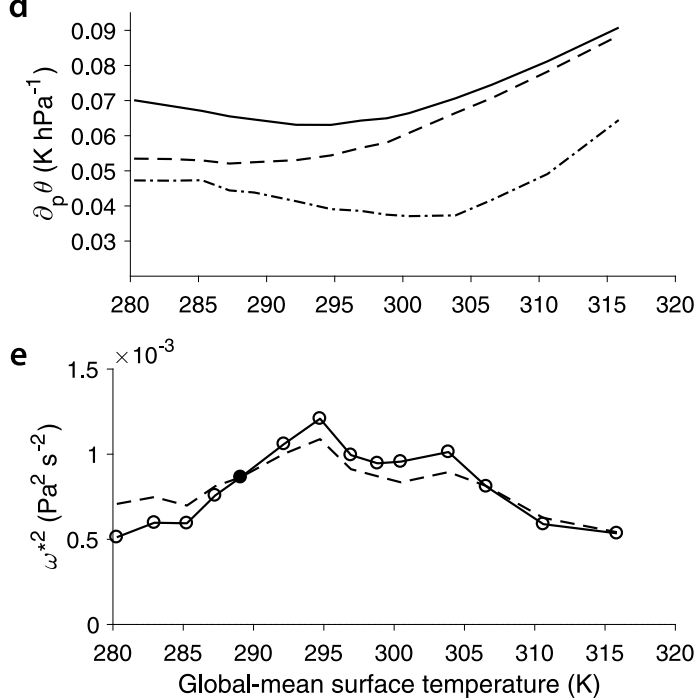
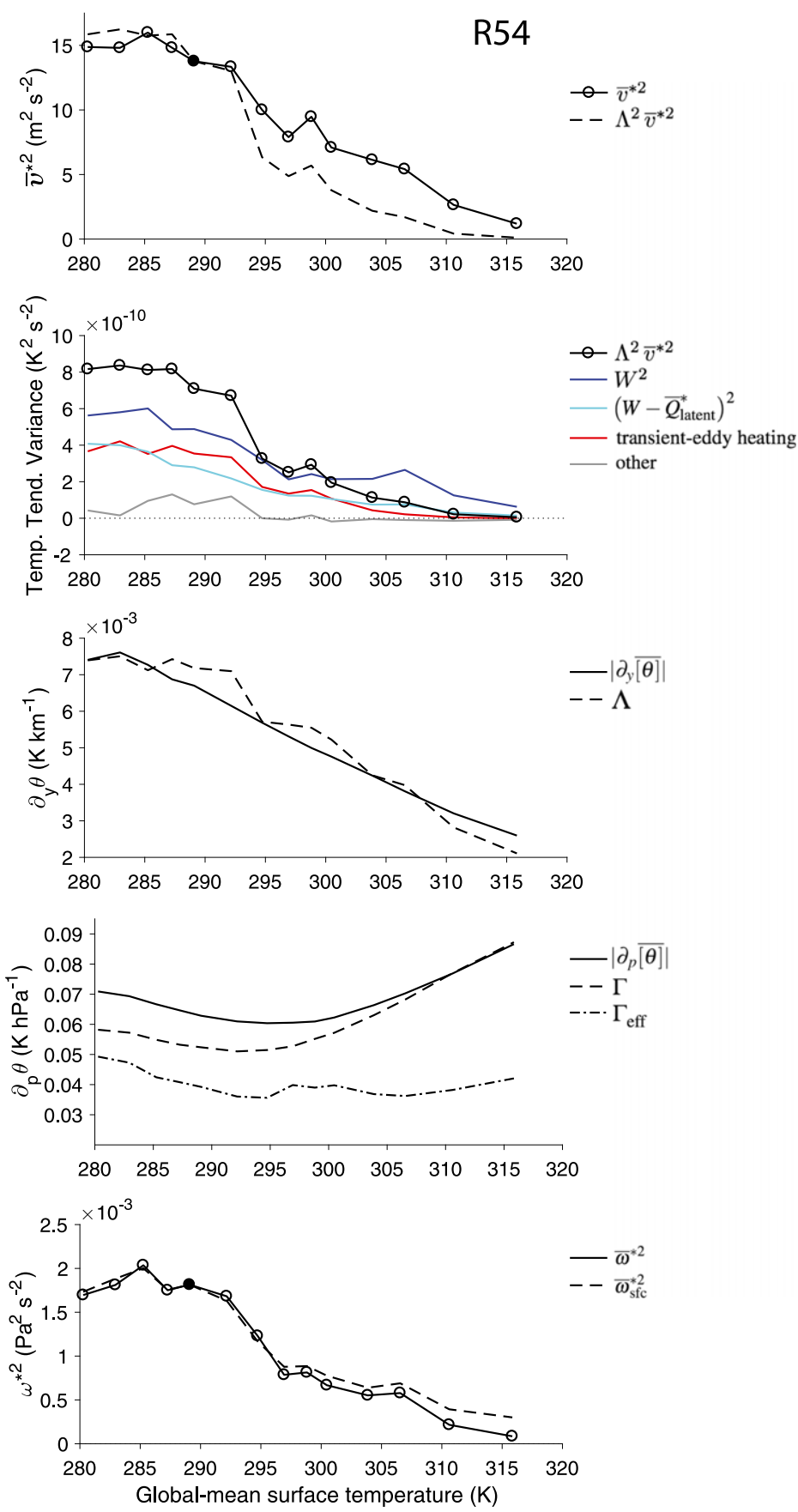

FIG. 9. Factors controlling the meridional wind response to vertical motions and zonally anomalous heating. (a) Meridional wind variance $\left\{\overline{\boldsymbol{v}}^{* 2}\right\}$ across the range of climates in both experiments (solid black line with circles) and the meridional wind variance that would result without changes in $\Lambda$ (dashed line; $\Lambda$ is fixed at its value in the reference climate, shown by the filled circle). (b) Variance of zonally anomalous temperature tendencies, which contribute to changes in $\left\{\overline{\boldsymbol{v}}^{* 2}\right\}$ according to Eq. (18) [see also Eq. (21)]. In each of these terms, we leave off the factor of $\Lambda^{-2}$ such that they sum to $\Lambda^{2}\left\{\bar{v}^{* 2}\right\}$, which is also shown in (a). Meridional temperature gradient changes must also be taken into account in deducing how these terms affect $\left\{\bar{v}^{* 2}\right\}$. (c) Behavior of the zonal-mean meridional temperature gradient $\left|\partial_{y} \overline{[\theta]}\right|$ and the effective meridional temperature gradient $\Lambda$ across the range of climates. (d) Behavior of the zonal-mean dry static stability $\left|\partial_{p}[\theta]\right|$, the effective static stability $\Gamma$ (accounting for zonal anomalies in stratification), and the effective static stability $\Gamma_{\text {eff }}$ (accounting for zonal anomalies in latent heating) across the range of climates. (e) Vertical wind variance $\left\{\bar{\omega}^{* 2}\right\}$ and a scaling that assumes it changes following changes in $\bar{\omega}_{\mathrm{sfc}}^{* 2}$, connecting the meridional wind variance budget to the analysis of the orographic vertical winds in section 4. Multiplying $\left\{\bar{\omega}^{* 2}\right\}$ by $\Gamma^{2 \mathrm{scc}}$ and $\Gamma_{\text {eff }}^{2}$ recover the blue and cyan lines in (b). All averaging is done over the layer immediately above the mountain $(550-750 \mathrm{hPa})$ within $5^{\circ}$ latitude and $25^{\circ}$ longitude of the mountain. 
from the vertical wind variance $\bar{\omega}^{* 2}$ and the zonalmean stratification. The vertical wind variance $\bar{\omega}^{* 2}$ scales with the vertical surface wind variance $\bar{\omega}_{\mathrm{sfc}}^{* 2}$ (Fig. 9e). Therefore, the dominant $W^{2}$ term is primarily determined by the orographic vertical velocities (discussed in the previous section) and the zonal-mean stratification, which generally decreases in the midlatitudes as the climate warms (Schneider and Walker 2008). The adiabatic cooling and heating differs between the two experiments primarily because of differences in orographic vertical velocity variance.

\section{b. Latent heating}

We analyze the effects of latent heating, transient eddies, and zonal advection by grouping the remaining terms according to

$$
\begin{aligned}
\left\{\bar{v}^{* 2}\right\} \approx & \frac{1}{\Lambda^{2}}\{W^{2}+\underbrace{\bar{Q}_{\text {latent }}^{* 2}-2 \bar{Q}_{\text {latent }}^{*} W}_{\text {latentheating }} \\
& +\underbrace{\bar{Q}_{\text {trans }}^{* 2}-2 \bar{Q}_{\text {trans }}^{*}\left(W-\bar{Q}_{\text {latent }}^{*}\right)}_{\text {transient-eddy heating }} \\
& +\underbrace{Z^{2}+\bar{Q}_{\text {other }}^{* 2}+2\left(Z-\bar{Q}_{\text {other }}^{*}\right)\left(W-\bar{Q}_{\text {latent }}^{*}-\bar{Q}_{\text {trans }}^{*}\right)}_{\text {other }}\},
\end{aligned}
$$

where $\bar{Q}_{\text {trans }}^{*} \equiv-\nabla_{\rho} \cdot\left(\overline{\mathbf{v}^{\prime} \theta^{\prime}}\right)^{*}$. In anticipation of the cancellation between adiabatic cooling and latent heating, we plot the net result of $W^{2}$ and the latent heating term, rather than the latent heating term by itself (cyan lines in Fig. 9b). The latent heating term reduces the stationaryeddy response throughout the range of climates. The transient-eddy heating term (red lines in Fig. 9b) is comparable in magnitude to the net forcing by vertical motions and latent heating, and shows a large decrease with climate change. It will be discussed in section $5 \mathrm{c}$. The zonal advection term $Z$ and the other diabatic terms, $\bar{Q}_{\text {other }}^{*}=\bar{Q}_{\text {radiation }}^{*}+\bar{Q}_{\text {sub-grid }}^{*}$, are small, but are needed for quantitative accuracy (gray lines in Fig. 9b). These terms are larger in the R45 experiment, where they arise primarily because of the $2 Z W$ term. This term represents the influence of zonal advection downstream of the mountain, where zonal-mean westerlies interact with a large cold anomaly (at approximately $135^{\circ}$ longitude), leading to heating to the west of the cold anomaly and cooling to the east (Fig. 7c). This heating (cooling) is in phase with the adiabatic cooling (heating) by orographic vertical motions and acts to strengthen the stationary wave.

The internal cancellation of adiabatic cooling and latent heating in vertical motions is a common property of circulations in moist atmospheres. One method to account for this cancellation is to define an effective static stability (Kiladis et al. 2009; O'Gorman 2011; Cohen and Boos 2016; Nie et al. 2016). In this zonally anomalous context, a requirement for defining an effective static stability is a strong correlation between anomalies in adiabatic cooling $-\bar{\omega}^{*} \partial_{p} \overline{[\theta]}$ and anomalies in latent heating, such that

$$
\bar{\omega}^{*} \partial_{p} \overline{[\theta]}-\bar{Q}_{\text {latent }}^{*} \approx \varepsilon \bar{\omega}^{*} \partial_{p} \overline{[\theta]} .
$$

The correlation between adiabatic cooling and latent heating ranges from $45 \%$ to $90 \%$ in these experiments, with the best agreement in the warmest climates. The effective static stability takes values of $\varepsilon=1$ in the dry limit, where latent heating is zero, and $\varepsilon=0$ in the limit where the adiabatic cooling is perfectly cancelled by latent heating.

We quantify the effective static stability felt by stationary-eddy circulations by defining

$$
\Gamma_{\text {eff }}^{2}(\phi, p)=\frac{\left\{\left(\bar{\omega}^{*} \partial_{p} \bar{\theta}-\bar{Q}_{\text {latent }}^{*}\right)^{2}\right\}}{\left\{\bar{\omega}^{* 2}\right\}} \equiv \varepsilon^{2} \Gamma^{2} .
$$

Latent heating reduces the effective static stability felt by stationary-eddy circulations throughout the range of climates (Fig. 9d). The difference between $\Gamma_{\text {eff }}$ and $\Gamma$ gets larger with warming as the moisture content of the atmosphere increases and latent heating becomes a leadingorder thermodynamic term. While this result is qualitatively intuitive, it remains a challenge to relate $\varepsilon$ explicitly to the moisture content of the atmosphere. As a consequence, $\Gamma_{\text {eff }}$ remains an empirical parameter, diagnosed from the simulations according to Eq. (23). In appendix B, we provide a more detailed discussion of the mechanisms leading to the correlation between zonally anomalous adiabatic cooling and latent heating within orographic stationary waves [Eq. (22)], and their role in determining $\varepsilon$.

The thermodynamic forcing of orographic stationary waves by zonal anomalies in adiabatic cooling/heating $W^{2}$ is reduced by zonal anomalies in latent heating. The net result, $\left(W-\bar{Q}_{\text {latent }}^{*}\right)^{2}$, is related to the vertical wind variance by $\Gamma_{\text {eff }}^{2}$ [Eq. (23)], which does not respond strongly to climate change (Fig. 9d). Combined with changes in vertical wind variance (Fig. 9e), the result is a nearconstant forcing by $\left(W-\bar{Q}_{\text {latent }}^{*}\right)^{2}$ in the R45 experiment and a strong monotonic decrease in $\left(W-\bar{Q}_{\text {latent }}^{*}\right)^{2}$ in the R54 experiment, the dominant factor in their differing $\left\{\bar{v}^{* 2}\right\}$ responses. 

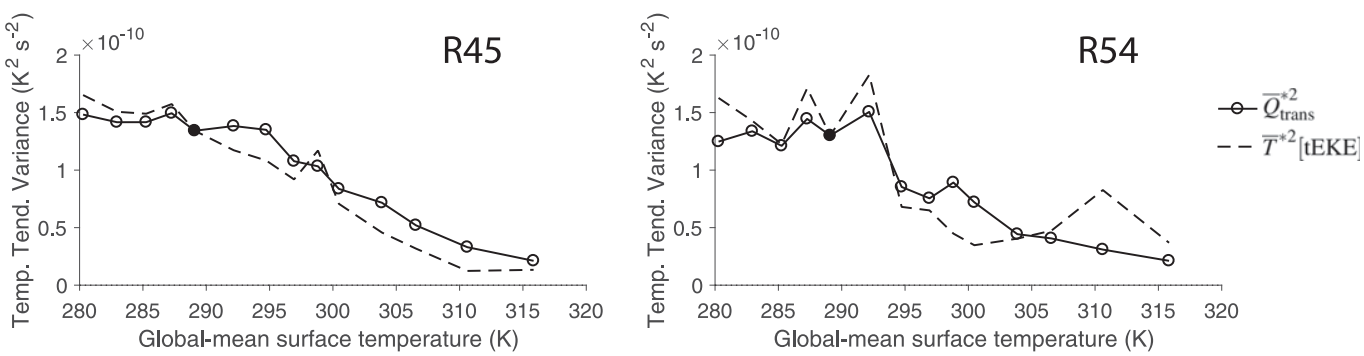

FIG. 10. Zonal variance of transient-eddy heat fluxes (solid line) and scaling based on Eq. (24) (dashed line), where we fix the scaling to be equal to the transient-eddy heat flux variance in the reference climate (filled circle). Averaging is done over the layer immediately above the mountain $(550-750 \mathrm{hPa})$ within $5^{\circ}$ latitude and $25^{\circ}$ longitude of the mountain.

\section{c. Transient-eddy heat fluxes}

The transient-eddy heating term is also important, accounting for about half of the stationary-eddy thermodynamic forcing throughout the range of climates (Fig. 9b). This amplification of stationary waves by transient-eddy heat fluxes results from downgradient heat fluxes into the cold region downstream of the mountain (Figs. 7 and 8). Because this heat flux convergence coincides with heating by adiabatic descent, it is in phase with the initial forcing and acts to strengthen the orographic stationary wave. The magnitude of the temperature anomaly and the resulting transient-eddy heat fluxes are proportional to the strength of the stationary-eddy winds, so these transient-eddy heat fluxes can be thought of as a positive feedback on the strength of stationary eddies. Note that we have not considered transient-eddy momentum fluxes, which can modify the climatological winds and overturning and thus influence other thermodynamic terms. For example, transient-eddy momentum fluxes likely play a role in determining $\bar{u}_{\mathrm{scc}}^{*}$ and thus $\bar{\omega}_{\mathrm{sfc}}^{*}$ [Eq. (6)].

Transient-eddy heat fluxes act diffusively in the zonal mean in that they increase as the pole-equator temperature gradient increases (Held 1999; Caballero and Langen 2005; Schneider and Walker 2008). If this were the case for the zonally anomalous transient-eddy heat fluxes in our idealized GCM experiments, the transienteddy heat flux convergence would be anticorrelated with the zonal temperature anomaly. This is qualitatively true, as shown by the downgradient heat fluxes into the cold region downstream of the mountain (Figs. 7 and 8). However, previous work has shown that this does not lead to a simple functional relationship between zonal temperature gradients and eddy fluxes (Lau and Wallace 1979). Overall, there is a weak anticorrelation between these quantities, but the transient-eddy heating has some smaller-scale structure near the mountain related to the enhanced meridional temperature gradient and the generation of baroclinic eddies. Nevertheless, transient-eddy heat fluxes are approximately diffusive on large scales such that we can make a scaling

$$
\bar{Q}_{\text {trans }}^{* 2} \sim \bar{T}^{* 2}[\mathrm{tEKE}]
$$

that describes the climate response of $\bar{Q}_{\text {trans }}^{* 2}$ over the mountain (Fig. 10) in terms of the zonal temperature variance $\bar{T}^{* 2}$ and the zonal-mean tEKE. The response of tEKE to climate change mirrors changes in mean available potential energy and has been discussed extensively elsewhere (Geng and Sugi 2003; Bengtsson et al. 2006; Schneider and Walker 2008; Li and Battisti 2008; O'Gorman and Schneider 2008a; Schneider et al. 2010; O'Gorman 2010; Mbengue and Schneider 2017). It does not play a large role in the decrease in lowertropospheric $\bar{Q}_{\text {trans }}^{* 2}$ with warming in our experiments, which is instead a consequence of the reduction in zonal temperature variance (discussed in section 6).

The coupling between stationary and transient eddies also plays an important role in the localization of storm tracks in the Northern Hemisphere (Son et al. 2009; Kaspi and Schneider 2013). The strong heat flux convergence downstream of the mountain results in part from the generation of eddies by baroclinic instability in this region of enhanced meridional temperature gradient. The enhanced baroclinicity helps to generate a localized storm track downstream, which terminates in the region of reduced baroclinicity west of the mountain (cf. Son et al. 2009; Kaspi and Schneider 2013). This interaction between transient eddies and stationary eddies was discussed extensively by Kaspi and Schneider (2013), who demonstrated the role of stationary waves in terminating a storm track forced by a warm ocean region in the midlatitudes. There is currently no simple theory for the coupling between stationary waves and midlatitude transient eddies. Such a theory would be required to make a closure for the influence of transient eddies on the strength of orographic stationary waves or to make a closed theory for the zonal variation of 


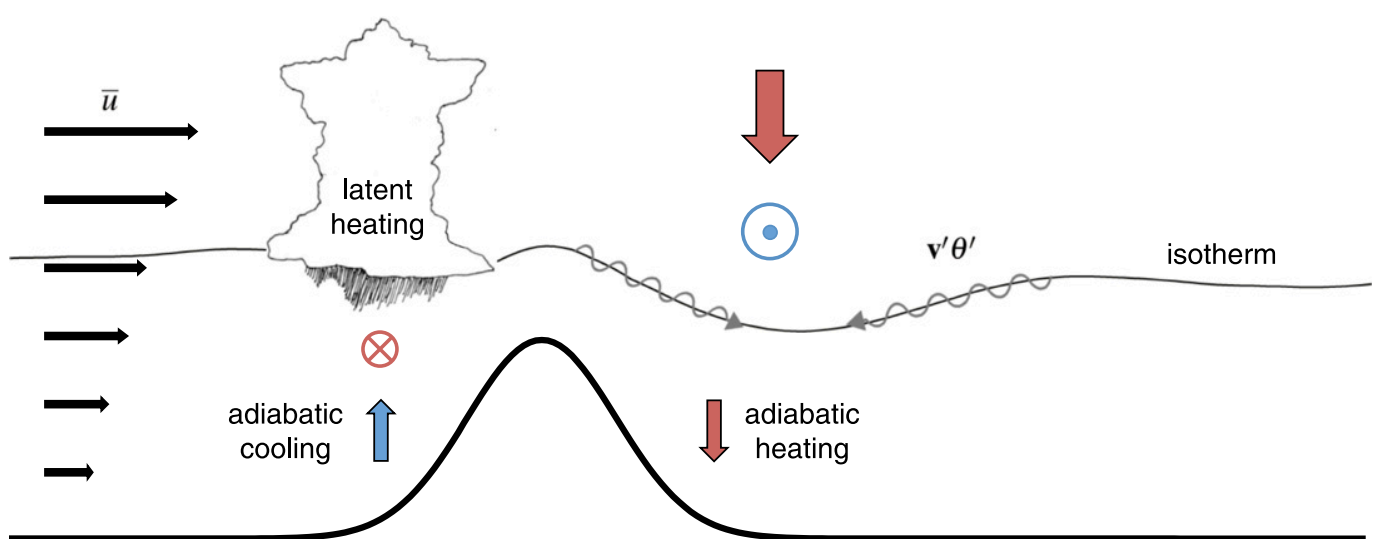

FIG. 11. Schematic of the effect of orography on stationary-eddy thermodynamics in the presence of westerly zonal winds (black arrows), overlain on a depiction of a single isotherm over the mountain (black line). Here, a circle with a cross (dot) denotes poleward (equatorward) advection and upward and downward arrows denote vertical motion. The response is asymmetric, with larger meridional winds on the downstream side of the mountain associated with a cold anomaly. Nonlinear terms such as the geostrophic intensification of the vertical wind aloft (big red arrow) and the transient-eddy heat fluxes (squiggly lines) act primarily in this downstream region, while latent heating acts in the upstream region. Processes are color coded red or blue based on whether they have a warming or cooling effect, respectively.

transient-eddy variance, as exists in the Northern Hemisphere storm tracks.

\section{d. Summary of mechanisms}

The meridional wind variance budget leaves us with a mechanistic picture of the tropospheric response to orographic forcing, illustrated schematically in Fig. 11. As surface winds impinge upon topography, they force adiabatic cooling (heating) as they ascend (descend) on topographic slopes. Stationary-eddy meridional velocities arise to balance this cooling/heating. Differences in the strength of surface winds and in the isentropic slope account for much of the difference in stationary wave strength with different forcing latitudes and different mean climate states. For the smaller isentropic slopes in warmer climates, larger meridional velocities are required to balance orographically forced ascent or descent, implying a strengthening of stationary waves with warming.

This picture is complicated by other types of heating, such as latent heating and transient-eddy heat fluxes. Latent heating on the windward slope is out of phase with the cooling/heating by adiabatic motions and thus acts as a negative feedback on stationary wave amplitude. Latent heating and the eastward group propagation of Rossby waves break the symmetry of the problem, leading to a northerly wind anomaly and cold anomaly downstream of the mountain [described in Hoskins and Karoly (1981) in the absence of latent heating], perturbations that propagate downstream according to Rossby wave dynamics. Through geostrophy, the northerly wind downstream of the mountain is associated with strong subsidence in the upper troposphere, which enhances adiabatic heating and amplifies the meridional velocity and temperature anomaly (cf. Fig. 7). Transient eddies act on the resulting temperature gradients, converging heat into the anomalous cold region. The transient-eddy heat flux convergence is in phase with the cooling/heating by adiabatic motions and thus acts as a positive feedback on stationary wave amplitude. The negative feedback from latent heating becomes stronger with warming because of increased atmospheric moisture content (section 5b; appendix B). The positive feedback from transient-eddy heat fluxes becomes weaker with warming because of reduced horizontal temperature gradients and reduced transient-eddy kinetic energy (section 5c). Both of these effects act to reduce the amplitude of orographic stationary eddies with warming.

\section{Influence on midlatitude zonal asymmetry}

Stationary-eddy winds play an important role in the zonal asymmetry of temperature and precipitation. In the simple case studied here, where stationary-eddy winds are forced by a single midlatitude mountain, the stationaryeddy winds weaken in warm, moist climates, leading to a reduction in zonal asymmetry across a range of latitudes. The changes in zonal asymmetry of temperature and precipitation result from a combination of the stationary-eddy wind changes and thermodynamic factors.

The implications of the wind changes in these simulations for changes in the zonal asymmetry of precipitation 
minus evaporation $(P-E)$ have been discussed extensively in WS16. There is a general tendency for the zonal variance of $P-E$ to increase as a result of the increase in atmospheric moisture content. Superimposed on this thermodynamic trend are any changes in stationary-eddy circulations, as characterized by the lower-tropospheric vertical winds (as shown in Fig. 9e). The zonal variance of $P-E$ thus increases with warming in moderate climates before decreasing again at most latitudes in warm, moist climates (Figs. 5 and 12 of WS16). Note that WS16 only studied the R45 experiment; there is an even larger decrease in zonal $P-E$ variance in the R54 experiment resulting from the larger decreases in lower-tropospheric vertical and horizontal winds (not shown).

Orographic vertical velocities exert a large influence on orographic net precipitation (i.e., $P-E$ on orographic slopes), through a term of the form

$$
\left(\bar{P}^{*}-\bar{E}^{*}\right)_{\text {orographic }} \approx-\frac{1}{g}\left(\bar{q}_{\mathrm{sfc}} \bar{\omega}_{\mathrm{sfc}}^{*}\right)^{*}
$$

where $q_{\text {sfc }}$ is the surface specific humidity (WS16). This contribution to orographic net precipitation can be further constrained by the scaling (7) for $\bar{\omega}_{\text {sfc }}^{*}$ in terms of the zonal-mean zonal surface winds and surface pressure gradients. However, as has been discussed in WS16, zonally anomalous transient-eddy moisture fluxes are large in the vicinity of topography. So while the changes in time-mean vertical velocities are too small to lead to much departure of orographic net precipitation from Clausius-Clapeyron scaling, the reduction in transient-eddy activity in the warmest climates leads to a reduction in net precipitation over orography (Fig. 12a of WS16). In the real world, where we expect a poleward migration of surface winds with global warming (Kushner et al. 2001; Yin 2005), the resulting changes in orographic vertical velocities through the scaling (7) could play a role in amplifying orographic $P-E$ at high latitudes while reducing it at lower latitudes.

Changes in the zonal variance of temperature also result from a combination of dynamic and thermodynamic factors. Based on a Taylor expansion, potential temperature anomalies $\bar{\theta}^{*}$ can to first order be expected to depend on the zonal-mean meridional gradient of potential temperature $\partial[\overline{[\theta]} / \partial y$ and a Lagrangian displacement length $L$ (Corrsin 1975; Schneider et al. 2015):

$$
\bar{\theta}^{*}=-L \frac{\partial \overline{[\theta]}}{\partial y} .
$$

In the context of stationary eddies, $L$ is the meridional displacement of a time-mean streamline (Hoskins and
Woollings 2015). We examine the root-mean-square (rms) of $\bar{\theta}^{*}$ at the midlatitudes in our simulations, which decreases with warming near the surface (Figs. 12a,b). It should scale with the zonal-mean temperature gradient according to

$$
\operatorname{rms}\left(\bar{\theta}^{*}\right) \sim L\left|\frac{\partial \overline{[\theta]}}{\partial y}\right| .
$$

The fractional reduction of the zonal-mean meridional temperature gradient in the lower troposphere (Figs. 12c,d) is comparable to the fractional reduction in $\operatorname{rms}\left(\bar{\theta}^{*}\right)$. Accordingly, changes in the Langrangian displacement length $L$, computed empirically, are small (Fig. 12e). This is partially explained by the lack of changes in stationary-eddy length scale in these simulations.

An alternative perspective is to think of the length scale $L$ as the product of a velocity scale and a time scale such that

$$
\operatorname{rms}\left(\bar{\theta}^{*}\right) \sim \tau \operatorname{rms}\left(\bar{v}^{*}\right)\left|\frac{\partial \bar{\theta}]}{\partial y}\right| .
$$

We have used the rms stationary-eddy meridional wind $\operatorname{rms}\left(\bar{v}^{*}\right)$ as a velocity scale. The time scale $\tau$ is the Lagrangian decorrelation time of stationary eddies (Swanson and Pierrehumbert 1997; Daoud et al. 2003) and provides a time scale of the processes acting to reduce the temperature anomalies created by stationaryeddy meridional advection, such as transient-eddy heat fluxes, zonal advection, and radiation. Fractional changes in $\operatorname{rms}\left(\bar{v}^{*}\right)$ at $850 \mathrm{hPa}$ are small (Fig. 12f) compared to fractional changes in the meridional temperature gradient. They are smaller than changes at higher levels, but not considerably [cf. Fig. 9; note that $\bar{v}^{* 2}$ is the square of $\left.\operatorname{rms}\left(\bar{v}^{*}\right)\right]$. Changes in the empirical dissipation time scale $\tau$ are also small (Fig. 12g). Zonal temperature variance changes are primarily determined by the reduction of the zonal-mean meridional temperature gradient with warming, with only small contributions from changes in dynamics, even in these idealized GCM simulations that show large changes in stationary-eddy winds across the range of climates. This is analogous to the reduction in temporal temperature variance with warming, which also results primarily from the reduction of the meridional temperature gradient rather than dynamic factors (Schneider et al. 2015). It should be kept in mind however, that a lack of dynamic influence on changes in zonal temperature variance does not preclude a large dynamic influence on local changes in temperature anomaly. Zonal temperature anomalies are tightly coupled to the stationary-eddy winds and will shift with shifting wind patterns. 

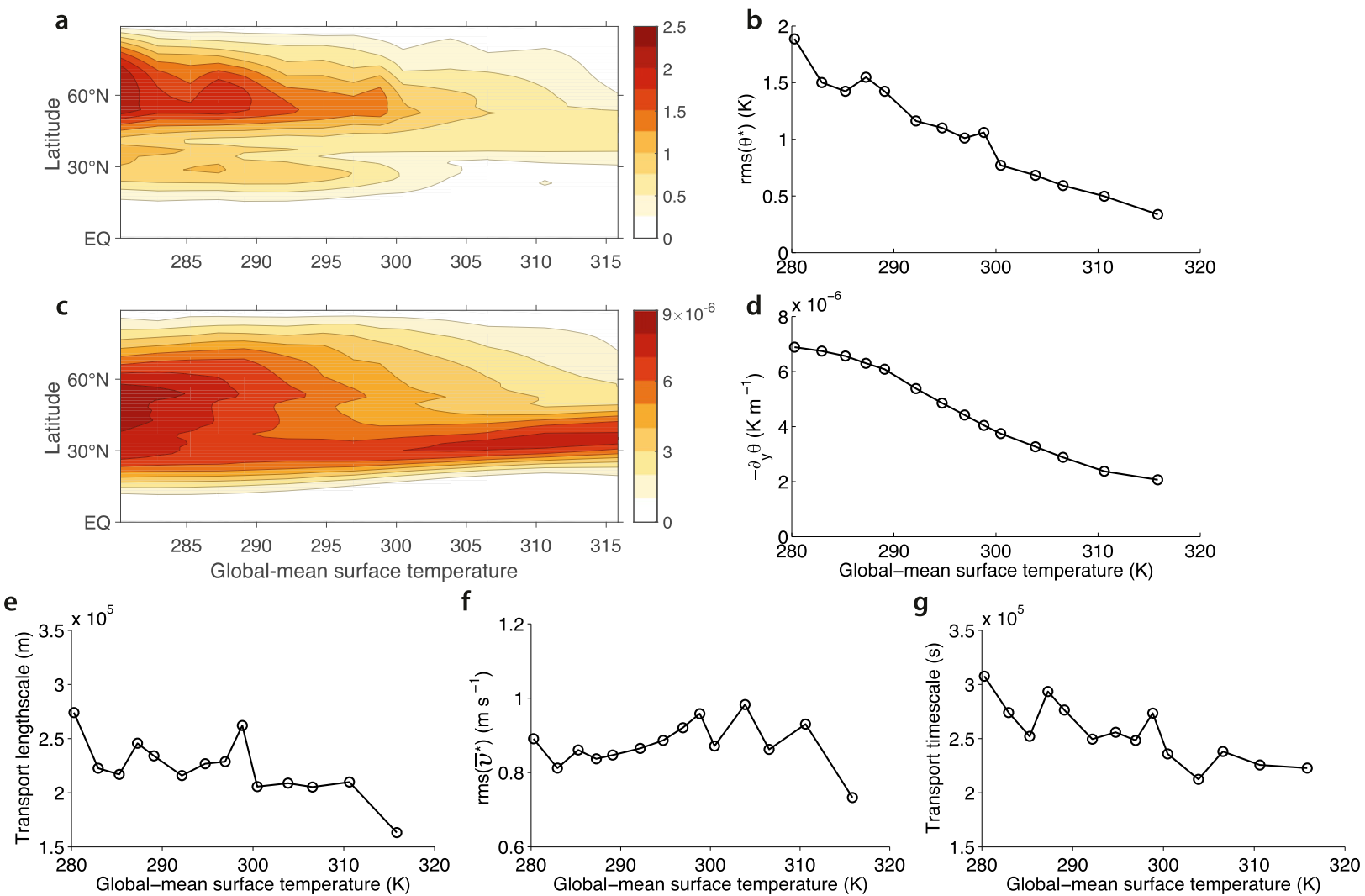

FIG. 12. (a) Root zonal variance of potential temperature $\operatorname{rms}\left(\theta^{*}\right)$ at $850 \mathrm{hPa}$ vs latitude in the R45 experiment and (b) an average over mid-to-high latitudes $\phi \in\left[45^{\circ}, 90^{\circ}\right]$. The zonal temperature variance decreases with warming. (c) Zonal-mean meridional temperature gradient $-\partial_{y} \overline{[\theta]}$ at $850 \mathrm{hPa}$ vs latitude in the R45 experiment and (d) an average over mid-to-high latitudes $\phi \in\left[45^{\circ}, 90^{\circ}\right]$. The temperature gradient decreases with warming. (e) The length scale obtained from dividing $\operatorname{rms}\left(\theta^{*}\right)$ by $-\partial_{y} \overline{[\theta]}$ at $850 \mathrm{hPa}$, which shows the lack of dynamic changes in zonal temperature variance. (f) Root zonal variance of meridional velocity $\operatorname{rms}\left(\bar{v}^{*}\right)$ at $850 \mathrm{hPa}$. (g) The time scale obtained by dividing the length scale in (e) by the velocity-scale $\operatorname{rms}\left(\bar{v}^{*}\right)$. All quantities in (e)-(g) are averaged over mid-to-high latitudes $\phi \in\left[45^{\circ}, 90^{\circ}\right]$.

\section{Summary and conclusions}

We have diagnosed the mechanisms governing the strength of stationary Rossby waves forced by midlatitude orography across a wide range of climates in an idealized GCM. To summarize, we group the most important influences on stationary wave amplitude by whether they increase or decrease the amplitude with warming.

1) Nonmonotonic change with warming:

- Change in zonal surface winds at the latitude of the mountain.

2) Decreased stationary wave amplitude with warming:

- Increased damping by latent heating.

- Reduced zonal variation of transient-eddy heat flux convergence as a result of reduced zonal temperature variance (resulting primarily from a reduced mean meridional temperature gradient) and reduced tEKE (in the warmest climates).

- Decreased top-of-mountain surface pressure due to mean warming.
3) Increased stationary wave amplitude with warming:

- Decreased isentropic slope resulting from increased extratropical static stability and reduced meridional temperature gradients.

The net result, after the internal cancellation of several of these effects, is that the amplitude of orographic stationary Rossby waves in these simulations scales roughly with the zonal-mean zonal surface winds because of their influence on orographic vertical winds. While the decrease in meridional temperature gradient and increase in extratropical static stability would both lead to an increased amplitude of orographic stationary Rossby waves, the increased damping by latent heating and reduced forcing by transient-eddy heat fluxes win out to give a reduction in strength of orographic stationary Rossby waves with global warming. While the relationship with zonal surface winds no longer applies for simulations where orography is equatorward of the band of surface westerlies, the same balance of physical mechanisms relates topographic vertical winds to 
the amplitude of orographic stationary Rossby waves (Wills 2016).

In understanding the influence of stationary waves on the zonal asymmetry of temperature and net precipitation, thermodynamic factors become leading order. Reduced meridional temperature gradients are associated with a reduction in the zonal asymmetry of temperature. Increased atmospheric moisture content is associated with an increase in zonal asymmetry of net precipitation. However, the reduced amplitude of orographic stationary Rossby waves is an important factor in reducing the zonal asymmetry of temperature and precipitation in the warmest, wettest climates.

\section{Implications}

There are numerous important differences between the idealized GCM used here and comprehensive models or the real atmosphere. For example, the idealized GCM simulates an equatorward shift of the surface westerlies with global warming (Fig. 6) while comprehensive models simulate a poleward shift (Yin 2005). However, all of the mechanisms discussed herein emerge from the governing physical equations and should have some relevance to the real climate system. Which of them can we expect to be important and which not? Because of the unusual equatorward shift of the surface westerlies, we do not expect the particular changes in surface winds and orographic vertical velocities in the R45 and R54 experiments to apply to realworld mountain ranges at these latitudes. We do, however, expect that the impinging zonal westerlies at the latitude of the mountain are the relevant surface winds to determine the strength of orographic forcing by midlatitude mountains. This may remain true even in cases where the zonal surface winds change sign, such as in the orographic forcing of Rossby waves by the Zagros Mountains in summer (Simpson et al. 2015).

In our simulations, the strength of the meridional wind response to orographic perturbations scales with the lower-tropospheric static stability and inversely with the meridional temperature gradient. This is a simple consequence of the thermodynamic equation and should equally apply to the real world. As an example of these mechanisms, recent work has shown that Mongolian topography matters more for the wintertime atmospheric circulation over the Pacific than the higher Tibetan Plateau because of the stronger surface winds and larger meridional temperature gradient at their higher latitude (White et al. 2017). The expected increase in static stability and decrease in lower-tropospheric meridional temperature gradients with global warming would both lead to an increase in the strength of orographic stationary waves. However, latent heating and transient-eddy heat fluxes must also be considered. In our simulations, increased damping by latent heating and reduced reinforcement by transient-eddy heat fluxes limits the strength of orographic stationary waves in warm climates. More work is needed to characterize latent heating and transient-eddy feedbacks within stationary waves in the real world.

Based on the mechanisms discussed in this study, the response of orographic stationary Rossby wave amplitude to climate change in the real climate system should depend on the surface wind, meridional temperature gradient, static stability, and latent heating changes in key regions around large-scale orography, such as the Rocky Mountains, Andes, Himalayas, Tibetan Plateau, and Mongolia, as well as on interactions between stationary wave changes and storm track changes. Cloud and water vapor feedbacks, which were not investigated here, could provide an additional influence on the amplitude of orographic stationary Rossby waves, through their role in the zonally anomalous energy budget, and should be investigated in this context.

Acknowledgments. This work was primarily completed while both authors were at the Department of Earth Sciences, ETH Zürich, Zurich, Switzerland. This research has also been supported by NSF Grant AGS1019211 while both authors were at the California Institute of Technology, Pasadena, California. The idealized GCM simulations for this study were performed on ETH Zürich's EULER computing cluster. Code for the idealized GCM is available online (at https://github. com/tapios/fms-idealized). We thank Simona Bordoni, Andy Thompson, Jess Adkins, Rachel White, Momme Hell, Farid Ait Chaalal, Ori Adam, and three anonymous reviewers for useful comments and discussion during the development of this manuscript.

\section{APPENDIX A}

\section{Interpolation to Pressure Coordinates}

While the idealized GCM uses sigma coordinates, we interpolate to pressure coordinates to avoid large spatial gradients on sigma surfaces as the coordinate surfaces slope over orography. The interpolation is done at every 6-hourly analysis time step, by linearly interpolating the vertical integral of each quantity. This helps ensure that mass is conserved in the interpolation. However, quantities with large vertical gradients, such as potential temperature, can be shifted in the vertical direction, creating large-amplitude grid-scale noise, which integrates to zero. The residual of the thermodynamic equation (11) after interpolation is shown in Fig. A1c. We distribute it to the 

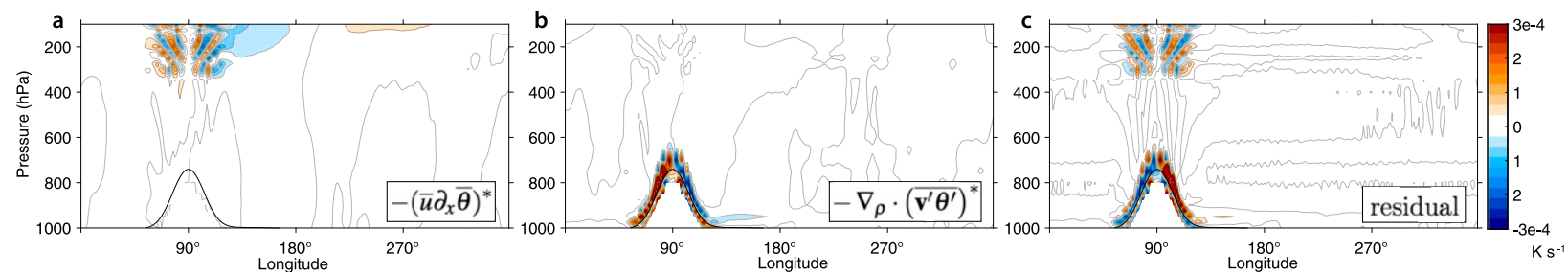

FIG. A1. Thermodynamic equation terms in the reference climate $\left(\alpha=1.0, T_{g}=289 \mathrm{~K}\right)$ of R45 before the residual has been distributed in a way such that the sum of variances of all terms is minimized. Note that the color bars are rescaled by a factor of 5 , as compared to Figs. 7 and 8.

other terms in a way that minimizes the total variance of all terms (i.e., we put the residual with the term it is most correlated with at each level). Above $600 \mathrm{hPa}$, this is the zonal advection term (Fig. A1a), which is noisy because of noise in $\bar{\theta}$. Below $600 \mathrm{hPa}$, this is the transient-eddy term, which is noisy because of the density weighted derivatives across the surface (Fig. A1b). The profiles shown in Figs. 7 and 8 are the result after distributing this residual.

\section{APPENDIX B}

\section{Derivation of the Relationship between Zonally Anomalous Latent Heating and Vertical Motions}

Here, we investigate the mechanisms linking zonally anomalous vertical motions and latent heating. We start with an expression for the instantaneous latent heating rate of an air parcel undergoing saturated ascent and conserving its equivalent potential temperature $\theta_{e}$,

$$
Q_{\text {latent }}=\left.\omega \frac{\partial \theta}{\partial p}\right|_{\theta_{e}} .
$$

This expression has been used in the context of precipitation extremes in climate model simulations (O'Gorman and Schneider 2009) and for deriving an effective static stability for midlatitude transient eddies (O'Gorman 2011). Assuming that upward motions always leads to saturation, we can write a more general expression for the latent heating rate that is valid for upward and downward motions,

$$
\left.Q_{\text {latent }} \approx \omega H(-\omega) \frac{\partial \theta}{\partial p}\right|_{\theta_{e}},
$$

where a Heaviside function $H(\cdot)$ has been introduced. The main approximation applied here is to assume that latent heating only occurs in association with upward motion, which is accurate to the extent that the meridional distance to saturation is large compared to the vertical distance to saturation.
Based on this latent heating approximation, the timeaverage zonally anomalous latent heating rate is given by

$$
\begin{aligned}
{\overline{Q_{\text {latent }}^{*}}}^{*} \overline{\omega^{\uparrow}} * \overline{\left[\left.\frac{\partial \theta}{\partial p}\right|_{\theta_{e}}\right]}+\left[\overline{\left.\omega^{\uparrow}\right]} \overline{\left.\frac{\partial \theta}{\partial p}\right|_{\theta_{e}} ^{*}}\right. \\
+\left(\overline{\left.\omega^{\uparrow} * \overline{\frac{\partial \theta}{\partial p}}\right|_{\theta_{e}} ^{*}}\right)^{*}+\overline{\left.\omega^{\uparrow^{\prime}} \frac{\partial \theta}{\partial p}\right|_{\theta_{e}} ^{\prime}},
\end{aligned}
$$

where $\omega^{\uparrow}=\omega H(-\omega)$. This expression would give rise to a simple expression for effective static stability if it were dominated by the first term and if the zonally anomalous gross upward mass flux ${\overline{\omega^{\uparrow}}}^{*}$ scaled with $\bar{\omega}^{*}$ (cf. O'Gorman 2011). However, the dominant term in Eq. (B3) is the fourth (transient-eddy) term, which explains $60 \%$ of the spatial variance in $\bar{Q}_{\text {latent }}^{*}$ near the mountain, ${ }^{4}$ while the first (zonally anomalous upward motion) term explains only $20 \%$. Time-mean zonal anomalies in the lapse rate at saturation play a role in the other $20 \%$ of the spatial variance in $\bar{Q}_{\text {latent }}^{*}$ The relevance of multiple terms here prevents a simple closed expression for $\varepsilon$ [Eq. (22)] in terms of thermodynamic factors.

It is still relevant to understand controls on $\overline{\omega^{\uparrow}}$, which we can relate to $\bar{\omega}$ by assuming a Gaussian pdf for $\omega$, with standard deviation $\sigma_{\omega}$, whereby

$$
\begin{aligned}
\overline{\omega^{\uparrow}} & =\overline{\omega H(-\omega)}=\int_{-\infty}^{0} \omega \operatorname{pdf}(\omega) d \omega \\
& =\frac{1}{2} \bar{\omega} \operatorname{erfc}\left(\frac{\bar{\omega}}{\sqrt{2} \sigma_{\omega}}\right)-\frac{\sigma_{\omega}}{\sqrt{2 \pi}} \exp \left(-\frac{\bar{\omega}^{2}}{2 \sigma_{\omega}^{2}}\right) .
\end{aligned}
$$

This expression can be understood by examining its limits. In the limit that the atmosphere is steady,

\footnotetext{
${ }^{4}$ These calculations are based on an additional four years of the R45 reference simulation, because $\overline{\omega^{\uparrow}}$ was not output for the other simulations. Averaging is done over the layer immediately above the mountain $(550-750 \mathrm{hPa})$ within $5^{\circ}$ latitude and $25^{\circ}$ longitude of the mountain.
} 
$\bar{\omega} / \sigma_{\omega} \rightarrow \infty$ and $\overline{\omega^{\uparrow}} \rightarrow \bar{\omega} H(-\bar{\omega})$ : the time-mean gross upward mass flux is given by the upward portion of the time-mean vertical velocity. In the limit of no time-mean vertical motion, $\bar{\omega} / \sigma_{\omega} \rightarrow 0$ and $\overline{\omega^{\uparrow}} \rightarrow-\sigma_{\omega} / \sqrt{2} \pi$ : the time-mean gross upward mass flux is proportional to the standard deviation of the vertical velocity. The typical time-mean vertical velocities near topography in these simulations are about $0.05 \mathrm{Pas}^{-1}$, or approximately $5 \mathrm{~mm} \mathrm{~s}^{-1}$, whereas a typical value for $\sigma_{\omega}$ is $3-4$ times that (0.15-0.2 $\left.\mathrm{Pa} \mathrm{s}^{-1}\right)$. This means that zonal anomalies in $\overline{\omega^{\uparrow}}$ come in a large part from zonal anomalies in vertical velocity statistics rather than from zonal anomalies in the climatological vertical velocity $\bar{\omega}$. Together with the importance of the transient-eddy term in Eq. (B3), this means that zonal anomalies in latent heating arise through the interaction between transient and stationary eddies, rather than directly from stationary-eddy vertical motions.

\section{REFERENCES}

Bender, F. A.-M., V. Ramanathan, and G. Tselioudis, 2012: Changes in extratropical storm track cloudiness 1983-2008: Observational support for a poleward shift. Climate Dyn., 38, 2037-2053, https://doi.org/10.1007/s00382-011-1065-6.

Bengtsson, L., K. I. Hodges, and E. Roeckner, 2006: Storm tracks and climate change. J. Climate, 19, 3518-3543, https://doi.org/ 10.1175/JCLI3815.1.

Boer, G. J., 1982: Diagnostic equations in isobaric coordinates. Mon. Wea. Rev., 110, 1801-1820, https://doi.org/10.1175/ 1520-0493(1982)110<1801:DEIIC > 2.0.CO;2.

Brandefelt, J., and H. Körnich, 2008: Northern Hemisphere stationary waves in future climate projections. J. Climate, 21, 6341-6353, https://doi.org/10.1175/2008JCLI2373.1.

Broccoli, A. J., and S. Manabe, 1992: The effects of orography on midlatitude Northern Hemisphere dry climates. J. Climate, 5, 1181-1201, https://doi.org/10.1175/1520-0442(1992)005<1181: TEOOOM $>2.0 . \mathrm{CO} ; 2$.

Caballero, R., and P. L. Langen, 2005: The dynamic range of poleward energy transport in an atmospheric general circulation model. Geophys. Res. Lett., 32, L02705, https://doi.org/ 10.1029/2004GL021581.

Chang, E. K. M., Y. Guo, and X. Xia, 2012: CMIP5 multimodel ensemble projection of storm track change under global warming. J. Geophys. Res., 117, D23118, https://doi.org/ 10.1029/2012JD018578.

Charney, J. G., and P. G. Drazin, 1961: Propagation of planetaryscale disturbances from the lower into the upper atmosphere. J. Geophys. Res., 66, 83-109, https://doi.org/10.1029/ JZ066i001p00083.

Chen, J., and S. Bordoni, 2014: Orographic effects of the Tibetan Plateau on the east Asian summer monsoon: An energetic perspective. J. Climate, 27, 3052-3072, https://doi.org/10.1175/ JCLI-D-13-00479.1.

Chen, S.-C., and K. E. Trenberth, 1988: Orographically forced planetary waves in the Northern Hemisphere winter: Steady state model with wave-coupled lower boundary formulation. J. Atmos. Sci., 45, 657-681, https://doi.org/10.1175/ 1520-0469(1988)045<0657:OFPWIT>2.0.CO;2.
Cohen, N. Y., and W. R. Boos, 2016: Perspectives on moist baroclinic instability: Implications for the growth of monsoon depressions. J. Atmos. Sci., 73, 1767-1788, https://doi.org/ 10.1175/JAS-D-15-0254.1.

Cook, K. H., and I. M. Held, 1988: Stationary waves of the ice age climate. J. Climate, 1, 807-819, https://doi.org/10.1175/ 1520-0442(1988)001<0807:SWOTIA > 2.0.CO;2.

Corrsin, S., 1975: Limitations of gradient transport models in random walks and in turbulence. Advances in Geophysics, Vol. 18A, Academic Press, 25-60, https://doi.org/10.1016/ S0065-2687(08)60451-3.

Daoud, W. Z., J. D. W. Kahl, and J. K. Ghorai, 2003: On the synopticscale Lagrangian autocorrelation function. J. Appl. Meteor., $\mathbf{4 2}$, 318-324, https://doi.org/10.1175/1520-0450(2003)042<0318: OTSSLA $>2.0 . \mathrm{CO} ; 2$.

Deser, C., A. S. Phillips, M. A. Alexander, and B. V. Smoliak, 2014: Projecting North American climate over the next 50 years: Uncertainty due to internal variability. J. Climate, 27, 22712296, https://doi.org/10.1175/JCLI-D-13-00451.1.

Egger, J., 1976: The linear response of a hemispheric two-level primitive equation model to forcing by topography. Mon. Wea. Rev., 104, 351-364, https://doi.org/10.1175/1520-0493(1976)104<0351: TLROAH $>2.0 . \mathrm{CO} ; 2$.

Frierson, D. M. W., 2007: The dynamics of idealized convection schemes and their effect on the zonally averaged tropical circulation. J. Atmos. Sci., 64, 1959-1976, https://doi.org/10.1175/ JAS3935.1.

— I. M. Held, and P. Zurita-Gotor, 2006: A gray-radiation aquaplanet moist GCM. Part I: Static stability and eddy scale. J. Atmos. Sci., 63, 2548-2566, https://doi.org/10.1175/ JAS3753.1.

Fyfe, J. C., 2003: Extratropical Southern Hemisphere cyclones: Harbingers of climate change? J. Climate, 16, 2802-2805, https:// doi.org/10.1175/1520-0442(2003)016<2802:ESHCHO > 2.0.CO;2.

Geng, Q., and M. Sugi, 2003: Possible change of extratropical cyclone activity due to enhanced greenhouse gases and sulfate aerosols-Study with a high-resolution AGCM. J. Climate, 16, 2262-2274, https://doi.org/10.1175/1520-0442(2003)16<2262: PCOECA $>2.0 . \mathrm{CO} ; 2$.

Held, I. M., 1983: Stationary and quasi-stationary eddies in the extratropical troposphere: Theory. Large Scale Dynamical Processes in the Atmosphere, B. Hoskins and R. Pearce, Eds., Academic Press, 127-168.

_- 1993: Large-scale dynamics and global warming. Bull. Amer. Meteor. Soc., 74, 228-241, https://doi.org/10.1175/ 1520-0477(1993)074<0228:LSDAGW>2.0.CO;2.

, 1999: The macroturbulence of the troposphere. Tellus, $\mathbf{5 1 B}$, 59-70, https://doi.org/10.3402/tellusb.v51i1.16260.

—_, and M. Ting, 1990: Orographic versus thermal forcing of stationary waves: The importance of the mean low-level wind. J. Atmos. Sci., 47, 495-500, https://doi.org/10.1175/ 1520-0469(1990)047<0495:OVTFOS > 2.0.CO;2.

— - R. L. Panetta, and R. T. Pierrehumbert, 1985: Stationary external Rossby waves in vertical shear. J. Atmos. Sci., 42 865-883, https://doi.org/10.1175/1520-0469(1985)042<0865: SERWIV $>2.0 . \mathrm{CO} ; 2$.

_ M. Ting, and H. Wang, 2002: Northern winter stationary waves: Theory and modeling. J. Climate, 15, 2125-2144, https://doi.org/ 10.1175/1520-0442(2002)015<2125:NWSWTA > 2.0.CO;2.

Hoskins, B. J., and D. J. Karoly, 1981: The steady linear response of a spherical atmosphere to thermal and orographic forcing. J. Atmos. Sci., 38, 1179-1196, https://doi.org/10.1175/ 1520-0469(1981)038<1179:TSLROA > 2.0.CO;2. 
—_ and T. Woollings, 2015: Persistent extratropical regimes and climate extremes. Curr. Climate Change Rep., 1, 115-124, https://doi.org/10.1007/s40641-015-0020-8.

IPCC, 2013: Climate Change 2013: The Physical Science Basis. Cambridge University Press, 1535 pp., https://doi.org/10.1017/ CBO9781107415324.

Joseph, R., M. Ting, and P. J. Kushner, 2004: The global stationary wave response to climate change in a coupled GCM. J. Climate, 17, 540-556, https://doi.org/10.1175/1520-0442(2004)017<0540: TGSWRT $>2.0 . \mathrm{CO} ; 2$.

Kaspi, Y., and T. Schneider, 2011: Winter cold of eastern continental boundaries induced by warm ocean waters. Nature, $\mathbf{4 7 1}$, 621-624, https://doi.org/10.1038/nature09924.

— midlatitude storm tracks. J. Atmos. Sci., 70, 2596-2613, https:// doi.org/10.1175/JAS-D-12-082.1.

Kiladis, G. N., M. C. Wheeler, P. T. Haertel, K. H. Straub, and P. E. Roundy, 2009: Convectively coupled equatorial waves. Rev. Geophys., 47, RG2003, https://doi.org/10.1029/2008RG000266; Corrigendum, 49, RG3004, https://doi.org/10.1029/2011RG000370.

Kushner, P. J., I. M. Held, and T. L. Delworth, 2001: Southern Hemisphere atmospheric circulation response to global warming. J. Climate, 14, 2238-2249, https://doi.org/10.1175/ 1520-0442(2001)014<0001:SHACRT $>2.0 . \mathrm{CO} ; 2$

Lau, N.-C., 1979: The observed structure of tropospheric stationary waves and the local balances of vorticity and heat. J. Atmos. Sci. 36, 996-1016, https://doi.org/10.1175/1520-0469(1979)036<0996: TOSOTS $>2.0 . \mathrm{CO} ; 2$

_ , and J. M. Wallace, 1979: On the distribution of horizontal transports by transient eddies in the Northern Hemisphere wintertime circulation. J. Atmos. Sci., 36, 1844-1861, https:// doi.org/10.1175/1520-0469(1979)036<1844:OTDOHT>2.0.CO;2.

Li, C., and D. S. Battisti, 2008: Reduced Atlantic storminess during Last Glacial Maximum: Evidence from a coupled climate model. J. Climate, 21, 3561-3579, https://doi.org/10.1175/ 2007JCLI2166.1; Corrigendum, 21, 6777, https://doi.org/ 10.1175/JCLI2811.1.

Lutsko, N. J., and I. M. Held, 2016: The response of an idealized atmosphere to orographic forcing: Zonal versus meridional propagation. J. Atmos. Sci., 73, 3701-3718, https://doi.org/ 10.1175/JAS-D-16-0021.1.

Mbengue, C., and T. Schneider, 2017: Storm-track shifts under climate change: Toward a mechanistic understanding using baroclinic mean available potential energy. J. Atmos. Sci., 74 93-110, https://doi.org/10.1175/JAS-D-15-0267.1.

Molnar, P., W. R. Boos, and D. S. Battisti, 2010: Orographic controls on climate and paleoclimate of Asia: Thermal and mechanical roles for the Tibetan Plateau. Annu. Rev. Earth Planet. Sci., 38, 77-102, https://doi.org/10.1146/annurev-earth-040809152456.

Nie, J., D. A. Shaevitz, and A. H. Sobel, 2016: Forcings and feedbacks on convection in the 2010 Pakistan flood: Modeling extreme precipitation with interactive large-scale ascent. J. Adv. Model. Earth Syst., 8, 1055-1072, https://doi.org/ 10.1002/2016MS000663.

Nigam, S., I. M. Held, and S. W. Lyons, 1986: Linear simulation of the stationary eddies in a general circulation model. Part I: The no-mountain model. J. Atmos. Sci., 43, 2944-2961, https:// doi.org/10.1175/1520-0469(1986)043<2944:LSOTSE>2.0.CO;2. - and 1988: Linear simulation of the stationary eddies in a GCM. Part II: The "mountain" model. J. Atmos. Sci., 45 1433-1452, https://doi.org/10.1175/1520-0469(1988)045<1433: LSOTSE $>2.0 . \mathrm{CO} ; 2$
O'Gorman, P. A., 2010: Understanding the varied response of the extratropical storm tracks to climate change. Proc. Natl. Acad. Sci. USA, 107, 19176-19180, https://doi.org/10.1073/ pnas. 1011547107

2011: The effective static stability experienced by eddies in a moist atmosphere. J. Atmos. Sci., 68, 75-90, https://doi.org/ 10.1175/2010JAS3537.1.

, and T. Schneider, 2008a: Energy of midlatitude transient eddies in idealized simulations of changed climates. J. Climate, 21, 5797-5806, https://doi.org/10.1175/2008JCLI2099.1.

, and - 2008b: The hydrological cycle over a wide range of climates simulated with an idealized GCM. J. Climate, 21, 3815-3832, https://doi.org/10.1175/2007JCLI2065.1.

— and - 2009: Scaling of precipitation extremes over a wide range of climates simulated with an idealized GCM. J. Climate, 22, 5676-5685, https://doi.org/10.1175/2009JCLI2701.1.

Peixóto, J. P., and A. H. Oort, 1983: The atmospheric branch of the hydrological cycle and climate. Variations in the Global Water Budget, A. Street-Perrott, M. Beran, and R. Ratcliffe, Eds., Springer, 5-65.

, and - 1992: Physics of Climate. American Institute of Physics, $520 \mathrm{pp}$.

Ringler, T. D., and K. H. Cook, 1997: Factors controlling nonlinearity in mechanically forced stationary waves over orography. J. Atmos. Sci., 54, 2612-2629, https://doi.org/10.1175/ 1520-0469(1997)054<2612:FCNIMF>2.0.CO;2.

Rodwell, M. J., and B. J. Hoskins, 2001: Subtropical anticyclones and summer monsoons. J. Climate, 14, 3192-3211, https:// doi.org/10.1175/1520-0442(2001)014<3192:SAASM>2.0.CO;2.

Schneider, T., and P. A. O'Gorman, 2008: Moist convection and the thermal stratification of the extratropical troposphere. J. Atmos. Sci., 65, 3571-3583, https://doi.org/10.1175/ 2008JAS2652.1.

, and C. C. Walker, 2008: Scaling laws and regime transitions of macroturbulence in dry atmospheres. J. Atmos. Sci., 65, 21532173, https://doi.org/10.1175/2007JAS2616.1.

_ P. A. O'Gorman, and X. J. Levine, 2010: Water vapor and the dynamics of climate changes. Rev. Geophys., 48, RG3001, https://doi.org/10.1029/2009RG000302.

- T. Bischoff, and H. Płotka, 2015: Physics of changes in synoptic midlatitude temperature variability. J. Climate, $\mathbf{2 8}$, 2312-2331, https://doi.org/10.1175/JCLI-D-14-00632.1; Corrigendum, 29, 3471, https://doi.org/10.1175/JCLI-D-16-0096.1.

Shi, X., and D. R. Durran, 2014: The response of orographic precipitation over idealized midlatitude mountains due to global increases in $\mathrm{CO}_{2}$. J. Climate, 27, 3938-3956, https://doi.org/ 10.1175/JCLI-D-13-00460.1.

Simpson, I. R., T. A. Shaw, and R. Seager, 2014: A diagnosis of the seasonally and longitudinally varying midlatitude circulation response to global warming. J. Atmos. Sci., 71, 2489-2515, https://doi.org/10.1175/JAS-D-13-0325.1.

, R. Seager, T. A. Shaw, and M. Ting, 2015: Mediterranean summer climate and the importance of Middle East topography. J. Climate, 28, 1977-1996, https://doi.org/10.1175/ JCLI-D-14-00298.1.

- — - M. Ting, and T. A. Shaw, 2016: Causes of change in Northern Hemisphere winter meridional winds and regional hydroclimate. Nat. Climate Change, 6, 65-70, https://doi.org/ 10.1038/nclimate2783.

Son, S.-W., M. Ting, and L. M. Polvani, 2009: The effect of topography on storm-track intensity in a relatively simple general circulation model. J. Atmos. Sci., 66, 393-411, https://doi.org/ 10.1175/2008JAS2742.1. 
Stephenson, D. B., and I. M. Held, 1993: GCM response of northern winter stationary waves and storm tracks to increasing amounts of carbon dioxide. J. Climate, 6, 1859-1870, https://doi.org/ 10.1175/1520-0442(1993)006<1859:GRONWS $>2.0$. CO;2.

Swanson, K. L., and R. T. Pierrehumbert, 1997: Lower-tropospheric heat transport in the pacific storm track. J. Atmos. Sci., 54, 1533-1543, https://doi.org/10.1175/1520-0469(1997)054<1533: LTHTIT>2.0.CO;2.

Ting, M., 1994: Maintenance of northern summer stationary waves in a GCM. J. Atmos. Sci., 51, 3286-3308, https://doi.org/ 10.1175/1520-0469(1994)051<3286:MONSSW>2.0.CO;2.

—_, and L. Yu, 1998: Steady response to tropical heating in wavy linear and nonlinear baroclinic models. J. Atmos. Sci., 55, 3565-3582, https://doi.org/10.1175/1520-0469(1998)055<3565: SRTTHI $>2.0 . \mathrm{CO} ; 2$.

Toumi, R., N. Hartell, and K. Bignell, 1999: Mountain station pressure as an indicator of climate change. Geophys. Res. Lett., 26, 1751-1754, https://doi.org/10.1029/1999GL900351.

Valdes, P. J., and B. J. Hoskins, 1989: Linear stationary wave simulations of the time-mean climatological flow. J. Atmos. Sci., 46, 2509-2527, https://doi.org/10.1175/1520-0469(1989)046<2509: LSWSOT $>2.0 . \mathrm{CO} ; 2$.

$\longrightarrow$, and — 1991: Nonlinear orographically forced planetary waves. J. Atmos. Sci., 48, 2089-2106, https://doi.org/10.1175/ 1520-0469(1991)048<2089:NOFPW>2.0.CO;2.

Vallis, G. K., 2006: Atmospheric and Oceanic Fluid Dynamics. Cambridge University Press, 745 pp.

Vecchi, G. A., and B. J. Soden, 2007: Global warming and the weakening of the tropical circulation. J. Climate, 20, 43164340, https://doi.org/10.1175/JCLI4258.1.
Wang, L., and P. J. Kushner, 2011: Diagnosing the stratospheretroposphere stationary wave response to climate change in a general circulation model. J. Geophys. Res., 116, D16113, https://doi.org/10.1029/2010JD015473.

White, R. H., D. S. Battisti, and G. H. Roe, 2017: Mongolian mountains matter most: Impacts of the latitude and height of Asian orography on Pacific wintertime atmospheric circulation. J. Climate, 30, 4065-4082, https://doi.org/10.1175/ JCLI-D-16-0401.1.

Wills, R. C., 2016: Stationary eddies and zonal variations of the global hydrological cycle in a changing climate. Ph.D. thesis, California Institute of Technology, $177 \mathrm{pp}$.

__ , and T. Schneider, 2015: Stationary eddies and the zonal asymmetry of net precipitation and ocean freshwater forcing. J. Climate, 28, 5115-5133, https://doi.org/10.1175/ JCLI-D-14-00573.1.

- , and —-, 2016: How stationary eddies shape changes in the hydrological cycle: Zonally asymmetric experiments in an idealized GCM. J. Climate, 29, 3161-3179, https://doi.org/ 10.1175/JCLI-D-15-0781.1.

_ M. P. Byrne, and T. Schneider, 2016: Thermodynamic and dynamic controls on changes in the zonally anomalous hydrological cycle. Geophys. Res. Lett., 43, 4640-4649, https:// doi.org/10.1002/2016GL068418.

— X. J. Levine, and T. Schneider, 2017: Local energetic constraints on Walker circulation strength. J. Atmos. Sci., 74, 1907-1922, https://doi.org/10.1175/JAS-D-16-0219.1.

Yin, J. H., 2005: A consistent poleward shift of the storm tracks in simulations of 21st century climate. Geophys. Res. Lett., 32, L18701, https://doi.org/10.1029/2005GL023684. 